\title{
A third sector in the core-periphery model: non-tradable goods
}

\author{
Vasco Leite • Sofia B. S. D. Castro • \\ João Correia-da-Silva
}

Received: 2 November 2010 / Accepted: 24 October 2011 / Published online: 12 November 2011

(C) Springer-Verlag 2011

\begin{abstract}
We extend an analytically solvable core-periphery model by introducing a monopolistically competitive sector of non-tradable goods that is mobile across regions. We find that when the elasticity of substitution among non-tradable goods is very low, there is agglomeration of all the production (of both tradable and non-tradable goods). When the elasticity of substitution among non-tradable goods is sufficiently high ("no black-hole" condition), then there is symmetric dispersion of all the production, if trade costs are high; or full agglomeration of the production of tradable goods with partial agglomeration of the production of non-tradable goods, if trade costs are low.
\end{abstract}

JEL Classification $\mathrm{F} 12 \cdot \mathrm{R} 12$

\footnotetext{
V. Leite

Comissão de Coordenação e Desenvolvimento Regional do Norte,

Rua Rainha D. Estefânia, 251, 4150-304 Porto, Portugal

e-mail: vasco.leite@ccdr-n.pt

V. Leite

Instituto Politécnico do Cávado e Ave,

Av. Dr. Sidonio Pais, 222, 4750-333 Barcelos, Portugal

S. B. S. D. Castro

CMUP and Faculdade de Economia, Universidade do Porto,

Rua Dr. Roberto Frias, 4200-464 Porto, Portugal

e-mail: sdcastro@fep.up.pt

J. Correia-da-Silva $(\varangle)$

CEF.UP and Faculdade de Economia, Universidade do Porto,

Rua Dr. Roberto Frias, 4200-464 Porto, Portugal

e-mail: joao@fep.up.pt
} 


\section{Introduction}

The literature on new economic geography has grown extensively over the last two decades, following the work of Krugman (1991), which illustrates how a country can endogenously become differentiated into an industrialized core and an agricultural periphery. ${ }^{1}$ In his model, trade costs are crucial to explain the spatial distribution of economic activity. If trade costs are high, industrial activity tends to be dispersed across regions, while if trade costs are low, the industrial activity tends to agglomerate in a single region.

Despite it being a stylized fact that services (which are mainly non-tradable) have a very significant weight in the developed economies, representing around $75 \%$ of the total employment in the EU27, the standard literature in new economic geography typically assumes that regions only have a perfectly competitive "agricultural" sector (which produces perfectly tradable goods ${ }^{2}$ ) and a monopolistically competitive "industrial" sector (which produces partially tradable goods). See for example, the works of Puga (1999), Fujita et al. (2001), Forslid and Ottaviano (2003), and Baldwin et al. (2003).

A notable exception is the work of Helpman (1998), who replaced the agricultural sector by a perfectly competitive non-tradable goods sector (housing). Assuming that the location of this sector is fixed, Helpman showed that housing acts as a dispersion force, by increasing the cost of living in a more populated region.

Similar results were obtained by Südekum (2006) and by Pflüger and Südekum (2008), who have also considered a perfectly competitive and immobile non-tradable goods sector, but now in addition to the traditional agricultural and industrial sectors. They showed that, starting from a situation of dispersion of industrial activity, falling trade costs lead to agglomeration. However, when trade costs become sufficiently low, the relative importance of housing prices dominates the agglomeration forces and dispersion occurs again. Contrasting with most new economic geography models, which feature "bang-bang" phenomena (either symmetric dispersion or full agglomeration of the industrial activity), the model of Pflüger and Südekum (2008) can generate partial agglomeration.

Recently, Cerina and Mureddu (2009) have extended the new economic geography and growth model of Baldwin et al. (2001) by incorporating an immobile and perfectly competitive non-tradable goods sector that benefits from local knowledge spillovers from the manufacturing sector. Their main result is that, with the existence of such a sector, agglomeration may be detrimental for growth.

Non-tradable goods also appear in the model of Behrens (2004). But, in this case, the absence of interregional trade is an endogenous outcome. Firms sell to those locations that allow them to make a positive profit, thus, depending on the level of trade costs and on the degree of competition, each good may be effectively traded (to another region) or not. Behrens (2004) showed that when the trade costs are higher than a

\footnotetext{
1 Space and geography had been considered in general equilibrium models long before that. See for example, Von Thünen (1826) and Takayama and Judge (1971).

2 Davis (1998) studied the importance of the assumption that "agricultural" goods are perfectly tradable and found that introducing a trade cost for "agricultural" goods makes the "home-market" effect disappear.
} 
threshold value, all the industrial goods are non-tradable. In such an environment, the economy comprises only an agricultural sector and a non-tradable goods sector. For this particular case, Behrens (2004) also showed that full and partial agglomeration in the non-tradable sector arises in a completely autarchic world, and that the structure of the spatial economy is determined by the ratio between the supply of the mobile factor and the supply of the immobile factor.

To the best of our knowledge, the only model that considers a mobile sector of nontradable goods is that of Tabuchi and Thisse (2006). ${ }^{3}$ They assume that all workers are mobile (across the two regions and the two sectors) and introduce a housing cost that increases with local population to generate a dispersion force. In contrast with the results that we provide here, they found that the non-tradable goods sector should become more agglomerated than the tradable goods sector.

We also seek to explain the spatial distribution of both tradable and nontradable goods, but in a different framework. We generalize the analytically solvable core-periphery model of Forslid and Ottaviano (2003) by incorporating a sector of non-tradable goods that is monopolistically competitive and mobile across regions, like the manufacturing sector. We will designate it as the "service sector," in spite of the fact that there are services that are tradable (for example, those that are internetbased). We refer, therefore, to non-tradable services such as education, health care, arts and entertainment, restaurants, housing, construction, urban transportation, retail, and administrative support.

With the workers that operate in the service sector (like those in the industrial sector) being able to move to the region with the highest utility level, we find that the resulting spatial configuration may be of full agglomeration, symmetric dispersion, or a combination of full agglomeration of industry with partial agglomeration of services.

A strong preference for variety in the service sector is a very strong agglomeration force. For any value of the manufacturing trade costs, full agglomeration of industry and services in one region is an equilibrium whenever the elasticity of substitution among services is lower than a threshold value ("black-hole" condition).

If the preference for variety of services is relatively weak ("no black-hole" condition), the manufacturing trade costs again become crucial to explain the location of economic activity. If these are high, industry and services become symmetrically dispersed across regions. If manufacturing trade costs are low, then the industry becomes agglomerated in one region, while services become partially agglomerated in the same region (core). Availability of more varieties of services in the core than in the periphery is an additional agglomeration force that prevents the industrial workers from moving to the periphery. Reciprocally, the proximity to manufacturing goods attracts the service sector workers, "distorting" the service sector toward the core.

\footnotetext{
3 In the previously mentioned works by Südekum (2006) and by Pflüger and Südekum (2008), the location of the non-tradable goods sector has been assumed to be fixed. This is a crucial difference, as the people in one region must then share the "cake" of services among themselves (in this case, services clearly act as a dispersion force). With service sector workers being mobile across regions, the distribution of this "cake" over across regions becomes endogenous.
} 
Our results contrast with those obtained for the case of an immobile supply of non-tradable goods (Helpman 1998; Südekum 2006; Pflüger and Südekum 2008), where these clearly acted as a dispersion force. To understand why, observe that an increase in the industrial activity in a region increases the demand for non-tradable goods in this region. If the supply is fixed, then the equilibrium is re-established through an increase in the price of non-tradable goods. This increases the cost of living of the industrial workers, thus acting as a dispersion force. If one considers that the supply of non-tradable goods is mobile, then an increase in the industrial activity in a region increases the demand for non-tradable goods, but also increases the supply (because the workers in the service sector are attracted by the greater availability of industrial goods at lower prices). Then, the non-tradable sector may either act as a dispersion force or as an agglomeration force.

In the standard literature, it is shown that when trade costs are low, the industry tends to agglomerate in a single region (core). The "cost-of-living" effect and the "home-market" effect dominate the "market-crowding" effect (the opposite occurs when trade costs are high). With a fixed supply of non-tradable goods, this is no longer true, because non-tradable goods become so expensive in the core and so cheap in the periphery that the industrial activity tends to disperse. Now, with the supply of non-tradable goods being mobile, the increase in the supply of non-tradable goods in the core compensates the increase in the demand. Therefore, the industry may still agglomerate fully (if the "cost-of-living" effect and the "home-market" effect dominate), while the service sector agglomerates only partially (because of the extreme strength of the "market-crowding" effect). ${ }^{4}$

To better understand what drives our results, it is useful to distinguish between localization economies, which induce an attraction between firms that operate in the same sector and urbanization economies, which induce an attraction between firms in general. Observe that the agglomeration forces that are at work in the core-periphery model, the "cost-of-living" effect, and the "home-market" effect are urbanization economies. On the other hand, the "market-crowding" effect only generates localization diseconomies, because there is no competition between firms that operate in different sectors-neither in the product markets nor in the labor markets. The partial agglomeration of the service sector in the core is such that the urbanization economies that result from locating in the region where all the industry is located is exactly compensated by the localization diseconomies that result from locating in a region with more competitors.

The rest of the paper is organized as follows. The model is presented in Sect. 2, together with the concepts of short-run and long-run equilibrium. In Sect. 3, the different possible long-run equilibria are described and the economic conditions that generate each kind of equilibrium are studied. The case in which services are partially tradable is briefly illustrated. In Sect. 4, some concluding remarks are made. All the technical proofs are presented in an "Appendix."

\footnotetext{
4 An empirical study of the "home-market" effect may be found in Davis and Weinstein (2003).
} 


\section{The model}

\subsection{Basic setup}

The model is an extension of the analytically solvable core-periphery model of Forslid and Ottaviano (2003) that incorporates a third sector of non-tradable goods ("services"). 5

The economy comprises two regions and three sectors: an "agricultural" sector (perfectly tradable goods), an "industrial" sector (partially tradable goods), and a "service" sector (non-tradable goods). There are three factors of production: immobile workers $(A)$, industrial sector workers $(M)$, and service sector workers $(S)$.

The agricultural sector is perfectly competitive and produces a homogeneous good under constant returns to scale using only immobile labor. The industrial sector and the service sector produce a horizontally differentiated product using sector-specific labor (fixed cost) and immobile labor (variable cost).

The transportation of agricultural output across regions is assumed to be costless, but the transportation of industrial goods and services is subject to iceberg transportation costs. For each unit of the industrial good that is shipped to the other region, only a fraction $\tau_{m} \in(0,1)$ arrives. The trade of services across regions is more costly: only a fraction $\tau_{s} \in\left[0, \tau_{m}\right]$ arrives. ${ }^{6}$ We will give particular attention to the case in which services are non-tradable across regions $\left(\tau_{s} \rightarrow 0\right)$.

In the long run, the industrial and service sector workers are mobile across regions (they migrate to the region where they attain a higher utility), contrarily to the immobile workers. In the short run, all workers are immobile.

We will denote by $M_{1}$ and $M_{2}$, with $M_{1}+M_{2}=M$, the number of industrial workers in regions 1 and 2, respectively, and by $S_{1}$ and $S_{2}$, with $S_{1}+S_{2}=S$, the number of service sector workers in regions 1 and 2, respectively. The number of immobile workers is the same in both regions, $A_{1}=A_{2}=A / 2$, and the total population is normalized to unity, $A+M+S=1$.

The nominal income in region $i$, denoted by $Y_{i}$, is the sum of the incomes of the immobile, industrial, and service sector workers. With their nominal wages denoted by $W_{a i}, W_{m i}$ and $W_{s i}$, respectively, we have

$$
Y_{i}=W_{a i} \frac{1-M-S}{2}+W_{m i} M_{i}+W_{s i} S_{i}, \quad \text { for } i \in\{1,2\} .
$$

\subsection{Demand}

\subsubsection{Preferences}

All the workers have the same preferences for the consumption of industrial goods $\left(C_{m}\right)$, services $\left(C_{s}\right)$, and agricultural goods $\left(C_{a}\right)$. A natural extension of the utility

\footnotetext{
${ }^{5}$ It will be straightforward to verify that by considering that the size of the "service" sector is null $\left(\mu_{s}=0\right)$, we obtain the model of Forslid and Ottaviano (2003).

${ }^{6}$ In Forslid and Ottaviano (2003) the model is set up, so that the parameter describing transportation costs is in $(1,+\infty)$ instead.
} 
function used by Krugman (1991) and by Forslid and Ottaviano (2003) to an economy with three sectors is the following: ${ }^{7}$

$$
\begin{aligned}
U & =C_{m}^{\mu_{m}} C_{s}^{\mu_{s}} C_{a}^{1-\mu_{m}-\mu_{s}}, \\
C_{m} & =\left(\sum_{k=1}^{n_{m}} c_{m_{k}}^{\frac{\sigma_{m}-1}{\sigma_{m}}}\right)^{\frac{\sigma_{m}}{\sigma_{m}-1}}, \\
C_{s} & =\left(\sum_{k=1}^{n_{s}} c_{s^{\frac{\sigma_{s}-1}{\sigma_{s}}}}\right)^{\frac{\sigma_{s}}{\sigma_{s}-1}}
\end{aligned}
$$

where $\mu_{m} \in(0,1)$ and $\mu_{s} \in(0,1)$, with $\mu_{m}+\mu_{s}<1$, are the shares of spending on industrial goods and on services; $n_{m}$ and $n_{s}$ are the number of existing varieties of industrial goods and of services; $c_{m_{k}}$ and $c_{s_{l}}$ are the consumption of the industrial good produced by firm $k$ and of the service provided by the firm $l$; and, finally, $\sigma_{m}>1$ and $\sigma_{s}>1$ are the elasticities of substitution among industrial goods and among services.

\subsubsection{Agricultural sector}

The price of the agricultural good is the same in both regions, as its transportation is assumed to be costless, ${ }^{8}$ and chosen to be the numeraire $\left(P_{a}=1\right)$.

The demand for agricultural goods in region $i$, which we denote by $C_{a i}$, results from utility maximization (2) with respect to $C_{a}$. Agents optimize by spending a share of their income in agricultural goods that is equal to $1-\mu_{m}-\mu_{s}$. Therefore,

$$
C_{a i}=P_{a}^{-1}\left(1-\mu_{m}-\mu_{s}\right) Y_{i}=\left(1-\mu_{m}-\mu_{s}\right) Y_{i}
$$

\subsubsection{Industrial sector}

The demand in region $i$ for the industrial variety $k$, which we denote by $c_{i}^{m_{k}}$, is obtained from utility maximization (3) with respect to $c_{m_{k}}$. It can be shown that (Baldwin et al. 2003, pp. 38-39):

$$
c_{i}^{m_{k}}=\left(p_{i}^{m_{k}}\right)^{-\sigma_{m}} \frac{\mu_{m} Y_{i}}{\sum_{k=1}^{n_{m}}\left(p_{i}^{m_{k}}\right)^{1-\sigma_{m}}},
$$

where $p_{i}^{m_{k}}$ is the price charged per unit of the industrial variety $k$ delivered in region $i$ and $Y_{i}$ is the regional income.

\footnotetext{
7 The same specification was chosen by Cerina and Mureddu (2009). An alternative could be the formulation considered by Tabuchi and Thisse (2006), in which the contributions of each sector are additive instead of multiplicative.

8 Davis (1998) shows that the basic properties of new economic geography models change when this technically convenient assumption is dispensed with.
} 
The industrial price index in region $i$ can be defined as:

$$
P_{m i}=\left[\sum_{k=1}^{n_{m}}\left(p_{i}^{m_{k}}\right)^{1-\sigma_{m}}\right]^{\frac{1}{1-\sigma_{m}}}
$$

Using (5), the demand in region $i$ for the industrial variety $k$ becomes

$$
c_{i}^{m_{k}}=\frac{\left(p_{i}^{m_{k}}\right)^{-\sigma_{m}}}{P_{m i}^{1-\sigma_{m}}} \mu_{m} Y_{i} .
$$

Since there is a large number of firms in the industrial sector, the price elasticity of demand is approximately equal to $\sigma_{m}$ (we have equality if there is a continuum of firms). ${ }^{9}$

\subsubsection{Service sector}

All the expressions obtained in the previous subsection apply. The only difference is that, later, the trade costs will be assumed to tend to infinity $\left(\tau_{s} \rightarrow 0\right) .{ }^{10}$

The demand in region $i$ for the service variety $k$ is given by:

$$
c_{i}^{s_{k}}=\frac{\left(p_{i}^{s_{k}}\right)^{-\sigma_{s}}}{P_{s i}^{1-\sigma_{s}}} \mu_{s} Y_{i},
$$

where $p_{i}^{s_{k}}$ is the price charged per unit of service $k$ delivered in region $i$ and the regional price index of services is $P_{s i}=\left[\sum_{k=1}^{n_{s}}\left(p_{i}^{s_{k}}\right)^{1-\sigma_{s}}\right]^{\frac{1}{1-\sigma_{s}}}$.

Again, we conclude that the price elasticity of demand is approximately equal to $\sigma_{s}$.

\subsection{Supply}

\subsubsection{Agricultural sector}

In the agricultural sector, firms use immobile labor to produce a homogeneous good under constant returns to scale. The production function is $q_{i}^{a}=L_{i}^{a}$, where $q_{i}^{a}$ is the amount of agricultural goods produced in region $i$ and $L_{i}^{a}$ is the quantity of labor employed. The cost function is $C T_{i}^{a}=W_{a i} q_{i}^{a}$ and the profit function is:

$$
\Pi_{i}^{a}=\left(P_{a}-W_{a i}\right) q_{i}^{a} .
$$

\footnotetext{
9 In the case of Cournot competition: $\frac{1}{\epsilon_{m}}=\frac{1}{\sigma_{m}}+s\left(1-\frac{1}{\sigma_{m}}\right)$, where $s$ is the market share of each firm. With many firms in the economy ( $s \approx 0$ ), the price elasticity of demand, $\epsilon_{m}$, is approximately equal to the elasticity of substitution, $\sigma_{m}$.

10 We do not consider directly the limit case because, with $\tau_{s}=0$, the demand of the agricultural workers is indeterminate when services are concentrated in the other region. When restricted to $C_{s}=0$, the agricultural workers are indifferent between any attainable consumption vector.
} 
The agricultural sector is perfectly competitive; therefore, $W_{a i}=P_{a}=1$.

\subsubsection{Industrial sector}

The firms in the industrial sector support a fixed cost of $\alpha_{m}$ units of industrial labor, and a variable cost of $\beta$ units of immobile labor per unit of good produced. ${ }^{11}$ Using the fact that $W_{a i}=1$, the cost function of the firm that produces variety $k$ in region $i$ is $C T_{i}^{m_{k}}=\alpha_{m} W_{m i}+\beta\left(q_{i i}^{m_{k}}+q_{i j}^{m_{k}} / \tau_{m}\right)$, where $q_{i i}^{m_{k}}$ is the quantity sold by the firm in the region where it is located and $q_{i j}^{m_{k}}$ is the quantity delivered to the other region. With $p_{i j}^{m_{k}}$ denoting the price at which the firm sells in each of the regions $j \in\{1,2\}$, the profit function is:

$$
\Pi_{i}^{m_{k}}=\left[p_{i i}^{m_{k}}\left(q_{i i}^{m_{k}}\right)-\beta\right] q_{i i}^{m_{k}}+\left[p_{i j}^{m_{k}}\left(q_{i j}^{m_{k}}\right)-\beta / \tau_{m}\right] q_{i j}^{m_{k}}-\alpha_{m} W_{m i}
$$

The firm chooses the quantities $q_{i i}^{m_{k}}$ and $q_{i j}^{m_{k}}$ with the objective of maximizing profits. Since the price elasticity of demand is a constant, $\sigma_{m}$, we have

$$
p_{i i}^{m_{k}}=\frac{\sigma_{m}}{\sigma_{m}-1} \beta \text { and } p_{i j}^{m_{k}}=\frac{\sigma_{m}}{\sigma_{m}-1} \frac{\beta}{\tau_{m}}=\frac{p_{i i}^{m_{k}}}{\tau_{m}} .
$$

Given the assumption of free entry, the profit of each firm must be zero. Substituting (9) in (8), we obtain the following:

$$
q_{i i}^{m_{k}}+\frac{q_{i j}^{m_{k}}}{\tau_{m}}=\frac{\alpha_{m}}{\beta}\left(\sigma_{m}-1\right) W_{m i} .
$$

Since an industrial firm employs $\alpha_{m}$ units of industrial labor, the number of industrial firms in region $i$ must be

$$
n_{m i}=\frac{M_{i}}{\alpha_{m}}
$$

\subsubsection{Service sector}

Firms in the service sector use $\alpha_{s}$ units of service sector workers as a fixed cost and $\beta$ units of immobile workers per unit of output.

As in the industrial sector, the prices charged by the service sector firm located in region $i$ that produces the variety $k$ are as follows:

$$
p_{i i}^{s_{k}}=\frac{\sigma_{s}}{\sigma_{s}-1} \beta \text { and } p_{i j}^{s_{k}}=\frac{\sigma_{s}}{\sigma_{s}-1} \frac{\beta}{\tau_{s}}=\frac{p_{i i}^{s_{k}}}{\tau_{s}} .
$$

\footnotetext{
11 It will become clear that setting $\alpha_{m}, \alpha_{s}$ (below) and $\beta$ to unity does not affect the spatial equilibrium outcomes. These productivity parameters are irrelevant (according to this model) to explain the agglomeration or dispersion of economic activity.
} 
The quantity produced by each firm is:

$$
q_{i i}^{s_{k}}+\frac{q_{i j}^{s_{k}}}{\tau_{s}}=\frac{\alpha_{s}}{\beta}\left(\sigma_{s}-1\right) W_{s i}
$$

And, the number of firms in region $i$ is:

$$
n_{s i}=\frac{S_{i}}{\alpha_{s}}
$$

\subsection{Short-run equilibrium concept}

In a short-run equilibrium, there is equality between supply and demand in all the labor markets and in all the goods markets, given the spatial distribution of industrial and service sector workers.

We have already used the equality between supply and demand in the three labor markets to find that $W_{a i}=1, n_{m i}=\frac{M_{i}}{\alpha_{m}}$ and $n_{s i}=\frac{S_{i}}{\alpha_{s}}$.

Below, we consider the equilibrium conditions in the markets for goods and services.

\subsubsection{Industrial sector}

Since all the industrial firms set the same prices, the industrial price index in region $i$ is:

$$
P_{m i}=\left[n_{m i}\left(p_{i i}^{m}\right)^{1-\sigma_{m}}+n_{m j}\left(p_{j i}^{m}\right)^{1-\sigma_{m}}\right]^{\frac{1}{1-\sigma_{m}}}=\frac{\beta \sigma_{m}}{\sigma_{m}-1}\left(n_{m i}+n_{m j} \tau_{m}^{\sigma_{m}-1}\right)^{\frac{1}{1-\sigma_{m}}}
$$

Defining $\phi_{m}=\tau_{m}^{\sigma_{m}-1}$ as the degree of economic integration for the industrial sector (Baldwin et al. 2003), we obtain: ${ }^{12}$

$$
P_{m i}=\alpha_{m}^{\frac{1}{\sigma_{m}-1}} \beta \frac{\sigma_{m}}{\sigma_{m}-1}\left(M_{i}+M_{j} \phi_{m}\right)^{\frac{1}{1-\sigma_{m}}}
$$

With the demand for an industrial product that is produced in region $i$ and consumed in region $j$ being denoted by $c_{i j}^{m}$, we have

$$
c_{i i}^{m}=\frac{\left(\frac{\beta \sigma_{m}}{\sigma_{m}-1}\right)^{-\sigma_{m}}}{P_{m i}^{1-\sigma_{m}}} \mu_{m} Y_{i} \text { and } \quad c_{i j}^{m}=\frac{\tau_{m}^{\sigma_{m}}\left(\frac{\beta \sigma_{m}}{\sigma_{m}-1}\right)^{-\sigma_{m}}}{P_{m j}^{1-\sigma_{m}}} \mu_{m} Y_{j}
$$

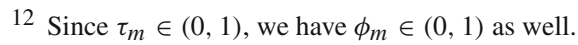


In equilibrium we must have

$$
q_{i i}^{m}+\tau_{m}^{-1} q_{i j}^{m}=c_{i i}^{m}+\tau_{m}^{-1} c_{i j}^{m}
$$

Substituting (10), (15), and (16) in (17), we obtain the nominal wage of the industrial workers in region $i$ :

$$
W_{m i}=\frac{\mu_{m}}{\sigma_{m}}\left(\frac{Y_{i}}{M_{i}+\phi_{m} M_{j}}+\frac{\phi_{m} Y_{j}}{\phi_{m} M_{i}+M_{j}}\right) .
$$

\subsubsection{Service sector}

Again, all the expressions obtained in the previous subsection apply.

The price index of services in region $i \in\{1,2\}$ is:

$$
P_{s i}=\alpha_{s}^{\frac{1}{\sigma_{s}-1}} \beta \frac{\sigma_{s}}{\sigma_{s}-1}\left(S_{i}+S_{j} \phi_{s}\right)^{\frac{1}{1-\sigma_{s}}}
$$

where $\phi_{s}=\tau_{s}^{\sigma_{s}-1}$ is the degree of economic integration in the service sector.

The internal and external demand for a service produced in region $i$ are given by:

$$
c_{i i}^{s}=\frac{\left(\frac{\beta \sigma_{s}}{\sigma_{s}-1}\right)^{-\sigma_{s}}}{P_{s i}^{1-\sigma_{s}}} \mu_{s} Y_{i} \text { and } c_{i j}^{s}=\frac{\tau_{s}^{\sigma_{s}}\left(\frac{\beta \sigma_{s}}{\sigma_{s}-1}\right)^{-\sigma_{s}}}{P_{s j}^{1-\sigma_{s}}} \mu_{s} Y_{j}
$$

And, the nominal wage of the service sector workers in region $i \in\{1,2\}$ is:

$$
W_{s i}=\frac{\mu_{s}}{\sigma_{s}}\left(\frac{Y_{i}}{S_{i}+\phi_{s} S_{j}}+\frac{\phi_{s} Y_{j}}{\phi_{s} S_{i}+S_{j}}\right) .
$$

\subsubsection{Perfect price index}

The perfect price index of region $i, P_{i}$, aggregates three price indices: the price index of the agricultural sector (normalized to 1), the price index of the industrial sector, $P_{m i}$, and the price index of the service sector, $P_{s i}$.

A worker in region $i$ spends his nominal wage $W$ to consume agricultural goods, industrial goods, and services by choosing $C_{a i}=\left(1-\mu_{m}-\mu_{s}\right) P_{a i}^{-1} W$, $C_{m i}=\mu_{m} P_{m i}^{-1} W$, and $C_{s i}=\mu_{s} P_{s i}^{-1} W$. Therefore, the utility that he attains is:

$$
U=\frac{W}{\left(1-\mu_{m}-\mu_{s}\right)^{1-\mu_{m}-\mu_{s}} \mu_{m}^{\mu_{m}} \mu_{s}^{\mu_{s}} P_{m i}^{-\mu_{m}} P_{s i}^{-\mu_{s}}} .
$$

Therefore, the perfect price index in region $i$ is:

$$
P_{i}=\left(1-\mu_{m}-\mu_{s}\right)^{1-\mu_{m}-\mu_{s}} \mu_{m}^{\mu_{m}} \mu_{s}^{\mu_{s}} P_{m i}^{-\mu_{m}} P_{s i}^{-\mu_{s}}
$$


Denoting the share of industrial workers in region 1 by $f_{m}=\frac{M_{1}}{M}$, we obtain:

$$
P_{m 1}=\frac{\beta \sigma_{m}}{\sigma_{m}-1}\left(\frac{M}{\alpha_{m}}\right)^{\frac{1}{1-\sigma_{m}}}\left[f_{m}+\left(1-f_{m}\right) \phi_{m}\right]^{\frac{1}{1-\sigma_{m}}}
$$

and

$$
P_{m 2}=\frac{\beta \sigma_{m}}{\sigma_{m}-1}\left(\frac{M}{\alpha_{m}}\right)^{\frac{1}{1-\sigma_{m}}}\left[\phi_{m} f_{m}+\left(1-f_{m}\right)\right]^{\frac{1}{1-\sigma_{m}}} .
$$

Similarly, defining $f_{s}=\frac{S_{1}}{S}$ as the share of service sector workers in region 1 , we obtain:

$$
P_{s 1}=\frac{\beta \sigma_{s}}{\sigma_{s}-1}\left(\frac{S}{\alpha_{s}}\right)^{\frac{1}{1-\sigma_{s}}}\left[f_{s}+\left(1-f_{s}\right) \phi_{s}\right]^{\frac{1}{1-\sigma_{s}}},
$$

and

$$
P_{s 2}=\frac{\beta \sigma_{s}}{\sigma_{s}-1}\left(\frac{S}{\alpha_{s}}\right)^{\frac{1}{1-\sigma_{s}}}\left[\phi_{s} f_{s}+\left(1-f_{s}\right)\right]^{\frac{1}{1-\sigma_{s}}} .
$$

Using these expressions, we obtain the perfect price indices for each region:

$$
P_{1}=\rho\left[f_{m}+\left(1-f_{m}\right) \phi_{m}\right]^{\frac{\mu_{m}}{1-\sigma_{m}}}\left[f_{s}+\left(1-f_{s}\right) \phi_{s}\right]^{\frac{\mu_{s}}{1-\sigma_{s}}},
$$

and

$$
P_{2}=\rho\left[\phi_{m} f_{m}+\left(1-f_{m}\right)\right]^{\frac{\mu_{m}}{1-\sigma_{m}}}\left[\phi_{s} f_{s}+\left(1-f_{s}\right)\right]^{\frac{\mu_{s}}{1-\sigma_{s}}},
$$

where $\rho=\frac{1}{\left(1-\mu_{m}-\mu_{s}\right)^{1-\mu_{m}-\mu_{s}} \mu_{m}^{\mu_{m}} \mu_{s}^{\mu_{s}}}\left(\frac{\beta \sigma_{m}}{\sigma_{m}-1}\right)^{\mu_{m}}\left(\frac{\beta \sigma_{s}}{\sigma_{s}-1}\right)^{\mu_{s}}\left(\frac{M}{\alpha_{m}}\right)^{\frac{\mu_{m}}{1-\sigma_{m}}}\left(\frac{S}{\alpha_{s}}\right)^{\frac{\mu_{s}}{1-\sigma_{s}}}$.

\subsubsection{Short-run equilibrium conditions}

Recall that, in the short run, workers are immobile across regions and that a short-run equilibrium consists in the equality of supply and demand in the labor markets and in the markets for goods and services. Prices, output, and wages are endogenously determined. 
Equations (1), (18), (21), (22), and (23) determine the short-run equilibrium of the model. We rewrite these equations:

$$
\begin{aligned}
Y_{1} & =\frac{1-M-S}{2}+W_{m 1} f_{m} M+W_{s 1} f_{s} S, \\
Y_{2} & =\frac{1-M-S}{2}+W_{m 2}\left(1-f_{m}\right) M+W_{s 2}\left(1-f_{s}\right) S, \\
W_{m 1} & =\frac{\mu_{m}}{\sigma_{m} M}\left[\frac{Y_{1}}{f_{m}+\phi_{m}\left(1-f_{m}\right)}+\frac{\phi_{m} Y_{2}}{\phi_{m} f_{m}+1-f_{m}}\right], \\
W_{m 2} & =\frac{\mu_{m}}{\sigma_{m} M}\left[\frac{Y_{2}}{1-f_{m}+\phi_{m} f_{m}}+\frac{\phi_{1}}{\phi_{m}\left(1-f_{m}\right)+f_{m}}\right], \\
W_{s 1} & =\frac{\mu_{s}}{\sigma_{s} S}\left[\frac{Y_{s} Y_{2}}{f_{s}+\phi_{s}\left(1-f_{s}\right)}+\frac{\phi_{2} Y_{1}}{\phi_{s} f_{s}+1-f_{s}}\right], \\
W_{s 2} & =\frac{\mu_{s}}{\sigma_{s} S}\left[\frac{Y_{2}}{1-f_{s}+\phi_{s} f_{s}}+\frac{\phi_{s}\left(1-f_{s}\right)+f_{s}}{\phi}\right], \\
P_{1} & =\rho\left[f_{m}+\left(1-f_{m}\right) \phi_{m}\right]^{\frac{\mu_{m}}{1-\sigma_{m}}}\left[f_{s}+\left(1-f_{s}\right) \phi_{s}\right]^{\frac{\mu_{s}}{1-\sigma_{s}}}, \\
P_{2} & =\rho\left[\phi_{m} f_{m}+\left(1-f_{m}\right)\right]^{\frac{\mu_{m}}{1-\sigma_{m}}}\left[\phi_{s} f_{s}+\left(1-f_{s}\right)\right]^{\frac{\mu_{s}}{1-\sigma_{s}}} .
\end{aligned}
$$

Solving these equations, we find the nominal wages of the workers in each region. The corresponding real wages (and utilities) are obtained simply by dividing the nominal wages by the regional price indices:

$$
\omega_{m 1}=\frac{W_{m 1}}{P_{1}}, \quad \omega_{m 2}=\frac{W_{m 2}}{P_{2}}, \omega_{s 1}=\frac{W_{s 1}}{P_{1}} \quad \text { and } \quad \omega_{s 2}=\frac{W_{s 2}}{P_{2}} .
$$

After obtaining general expressions for the regional wages in each sector, we let $\phi_{s} \rightarrow 0$ to study the case in which services are non-tradable. ${ }^{13}$

\subsection{Long-run equilibrium concept}

In the long run, the industrial and service sector workers choose their location with the objective of maximizing their utility (equivalently, they choose the region with the highest real wage).

The values of $f_{m}$ and $f_{s}$ are no longer exogenous. For concreteness, it may be assumed that the migration is driven by the following processes:

$$
\dot{f}_{m}=\frac{d f_{m}}{d t}= \begin{cases}\omega_{m 1}\left(f_{s}, f_{m}\right)-\omega_{m 2}\left(f_{s}, f_{m}\right), & \text { if } 0<f_{m}<1 \\ \min \left\{0, \omega_{m 1}\left(f_{s}, f_{m}\right)-\omega_{m 2}\left(f_{s}, f_{m}\right)\right\}, & \text { if } f_{m}=1 \\ \max \left\{0, \omega_{m 1}\left(f_{s}, f_{m}\right)-\omega_{m 2}\left(f_{s}, f_{m}\right)\right\}, & \text { if } f_{m}=0\end{cases}
$$

\footnotetext{
13 See the Appendix for detailed calculations.
} 
and

$$
\dot{f}_{s}=\frac{d f_{s}}{d t}= \begin{cases}\omega_{s 1}\left(f_{s}, f_{m}\right)-\omega_{s 2}\left(f_{s}, f_{m}\right), & \text { if } 0<f_{s}<1 \\ \min \left\{0, \omega_{s}\left(f_{s}, f_{m}\right)-\omega_{s 2}\left(f_{s}, f_{m}\right)\right\}, & \text { if } f_{s}=1 \\ \max \left\{0, \omega_{s 1}\left(f_{s}, f_{m}\right)-\omega_{s 2}\left(f_{s}, f_{m}\right)\right\}, & \text { if } f_{s}=0 .\end{cases}
$$

A distribution of economic activity, $\left(f_{s}^{*}, f_{m}^{*}\right)$, is a steady state if and only if $\dot{f}_{m}=\dot{f}_{s}=0$ at $\left(f_{s}^{*}, f_{m}^{*}\right)$. A long-run equilibrium is a stable steady state.

The following are sufficient conditions for stability:

(i) if $f_{x}^{*}=0$, then $\omega_{x 1}\left(f_{x}^{*}, f_{y}^{*}\right)<\omega_{x 2}\left(f_{x}^{*}, f_{y}^{*}\right)$, for $(x, y) \in\{(s, m),(m, s)\}$;

(ii) if $f_{x}^{*}=1$, then $\omega_{x 1}\left(f_{x}^{*}, f_{y}^{*}\right)>\omega_{x 2}\left(f_{x}^{*}, f_{y}^{*}\right)$, for $(x, y) \in\{(s, m),(m, s)\}$;

(iii) if $f_{x}^{*} \in(0,1) \wedge f_{y}^{*} \in\{0,1\}$, then $\left.\frac{\partial\left(\omega_{x 1}-\omega_{x 2}\right)}{\partial f_{x}}\right|_{\left(f_{x}^{*}, f_{y}^{*}\right)}<0$, for $(x, y) \in$ $\{(s, m),(m, s)\}$;

(iv) if $f_{m}^{*} \in(0,1) \wedge f_{s}^{*} \in(0,1)$, then $\left.\operatorname{det}(J)\right|_{\left(f_{m}^{*}, f_{s}^{*}\right)}>0$ and $\left.\operatorname{tr}(J)\right|_{\left(f_{m}^{*}, f_{s}^{*}\right)}<0$, where:

$$
J=\left[\begin{array}{ll}
\frac{\partial\left(\omega_{m 1}-\omega_{m 2}\right)}{\partial f_{m}} & \frac{\partial\left(\omega_{m 1}-\omega_{m 2}\right)}{\partial f_{s}} \\
\frac{\partial\left(\omega_{s 1}-\omega_{s 2}\right)}{\partial f_{m}} & \frac{\partial\left(\omega_{s 1}-\omega_{s 2}\right)}{\partial f_{s}}
\end{array}\right]
$$

Therefore, all these derivatives are well defined. The differences $\omega_{m 1}-\omega_{m 2}$ and $\omega_{s 1}-\omega_{s 2}$ are continuous and differentiable functions of $f_{m}$ and $f_{s}$, for $\left(f_{s}, f_{m}\right) \in$ $(0,1) \times(0,1) .^{14}$

\section{Long-run equilibrium}

Focusing on the case in which services are non-tradable, we show that the following are possible long-run equilibrium configurations (see Fig. 1):

(i) full agglomeration of industry and services in the same region;

(ii) full agglomeration of industry and partial agglomeration of services in the same region;

(iii) symmetric dispersion of industry and services.

In what follows we shall describe the long-run equilibrium configurations and also the combination of parameters that favors each of them. While the study of transitions between two different configurations is a pertinent question, it requires the study of the bifurcations, or break points, in a model with two state variables, $f_{m}$ and $f_{s}$. This requires a more sophisticated analysis of the Jacobian matrix at each configuration and would go beyond the scope of this paper. We plan to address this issue in the future.

\footnotetext{
14 Inspection of the expressions for $\omega_{m 1}-\omega_{m 2}$ and $\omega_{s 1}-\omega_{s 2}$ shows that continuity of these differences and their derivatives depends on the denominator in (41) not being zero. This is the case because $K_{1}$ and $K_{2}$ are positive.
} 


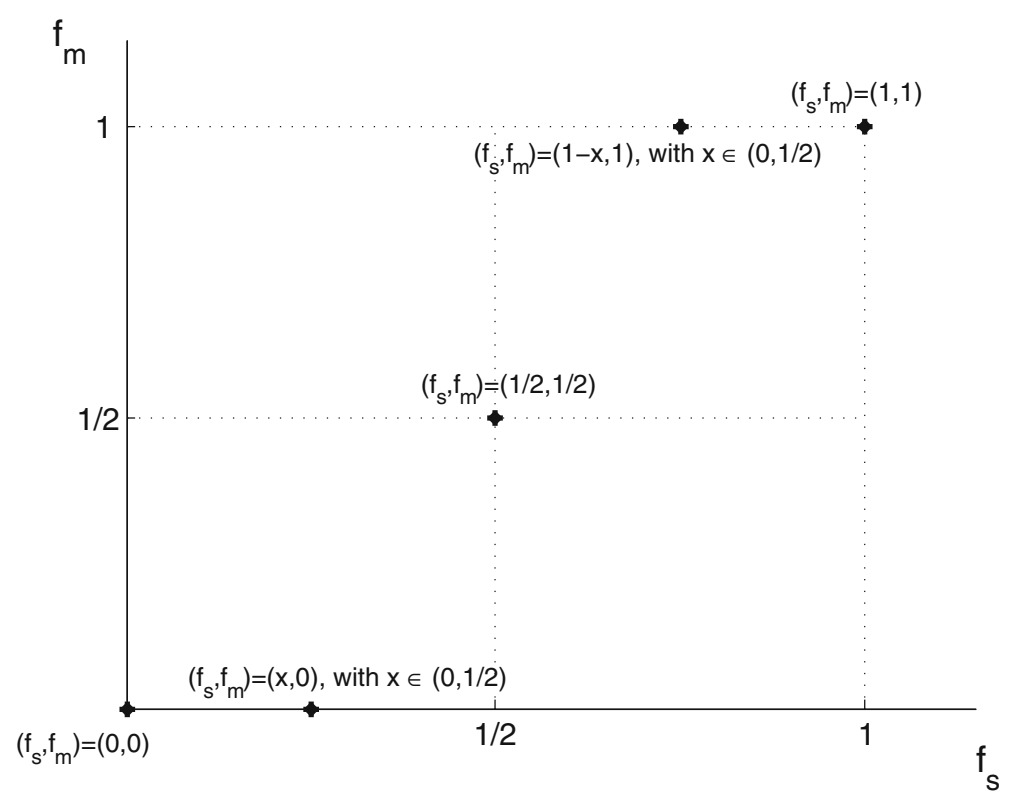

Fig. 1 Possible equilibrium configurations: full agglomeration, symmetric dispersion, and full agglomeration of industry with partial agglomeration of services

3.1 Agglomeration of industry and services in the same region

Agglomeration of the industrial and service activity in region 1 is an equilibrium if, with $\left(f_{s}^{*}, f_{m}^{*}\right)=(1,1)$, the real wages are higher in this region $\left(\omega_{m 1}>\omega_{m 2}\right.$ and $\left.\omega_{s 1}>\omega_{s 2}\right)$.

We find that full agglomeration only occurs if a "no black-hole" condition is violated (see the proof in Appendix).

Lemma 1 Agglomeration of both sectors in a single region is an equilibrium if and only if $\mu_{s} \geq \sigma_{s}-1$.

In the model of Forslid and Ottaviano (2003), which we extend, agglomeration always prevails unless $\mu_{m}<\sigma_{m}-1$ (the "no black-hole" condition). We have found that, with the incorporation of a non-tradable goods sector, the "no black-hole" condition becomes $\mu_{s}<\sigma_{s}-1$. The only difference is that the relevant parameters are those of the non-tradable goods sector. The former condition, $\mu_{m}<\sigma_{m}-1$, is no longer necessary to avoid agglomeration.

This result also shows that trade costs in the industrial sector are irrelevant to explain a simultaneous agglomeration of industry and services in a single region. Independently of the trade costs in the industrial sector, a high (low) preference for variety of services induces (avoids) full agglomeration of industry and services.

Why does a high preference for variety of services promote agglomeration? Recall that agglomeration occurs if the "home-market" effect and the "cost-of-living" effect dominate the "market-crowding" effect. Observe that the ratio between the nominal 


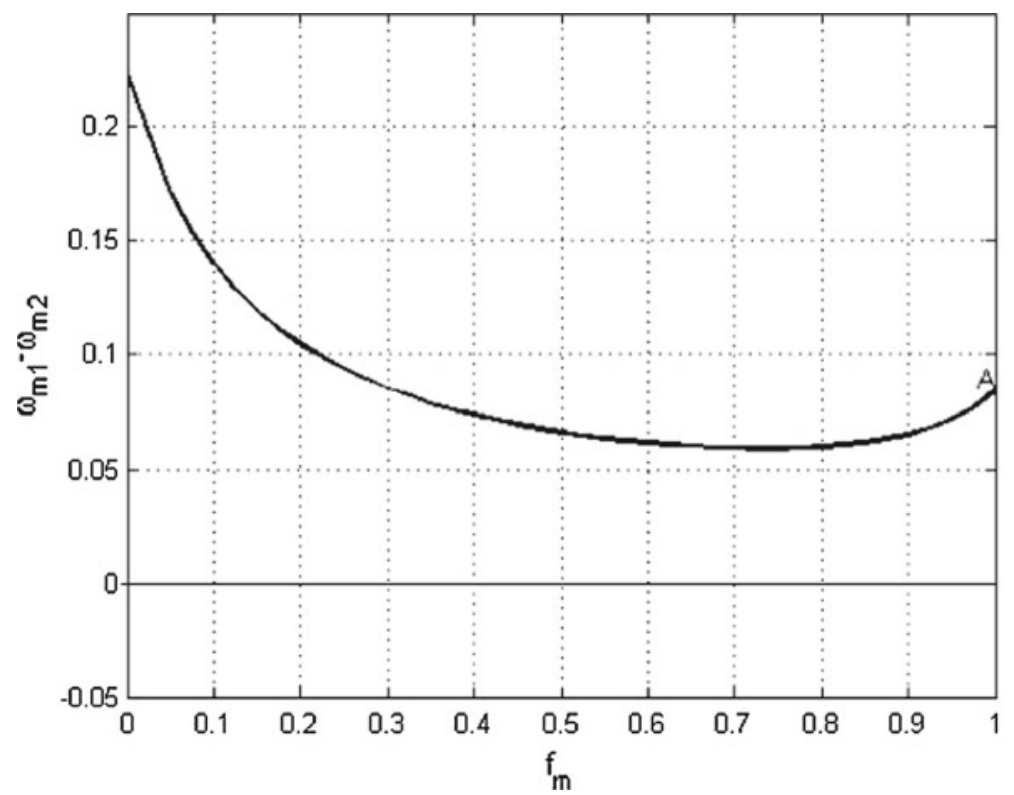

Fig. 2 Agglomeration of industry

wages, $\frac{W_{s 1}}{W_{s 2}}$, is inversely proportional to $\frac{f_{s}}{1-f_{s}}$, independently of the value of $\sigma_{s}$ (to find this, substitute (1) in (21), set $\phi_{s}=0$ and solve for each $W_{s i}$ ). This is obviously a dispersion force, reflecting the dominance of the "market-crowding" effect over the "home-market" effect. On the other hand, the price ratio, $\frac{P_{1}}{P_{2}}$, is inversely proportional to $\left(\frac{f_{s}}{1-f_{s}}\right)^{\frac{\mu_{s}}{\sigma_{s}-1}}$. It is an agglomeration force that more than compensates the dispersion force if and only if $\frac{\mu_{s}}{\sigma_{s}-1}>1$. The global effect is clear by the inspection of expression (42), according to which the real wage in the service sector is proportional to $f_{s}^{\frac{\mu_{s}}{\sigma_{s}-1}-1}$. If there is agglomeration of services, agglomeration of industry follows as a consequence (because $U=0$ in a region without services).

Figures 2 and 3 illustrate the existence of full agglomeration of the industrial and service activity in one region when $\mu_{s} \geq \sigma_{s}-1 .^{15}$

In Fig. 2, we assume that all the services are concentrated in region $1, f_{s}=1$, and we study the relationship between the spatial distribution of industry and the difference between the real wages of the industrial workers across regions. We find that the real wage is always higher in region 1. Thus, all industrial workers migrate to region 1.

In Fig. 3, we assume that all the industry is concentrated in region $1, f_{m}=1$, and we study how the spatial distribution of services affects the difference between the real wages of the service sector workers across regions. We find that if the service sector activity in region 1 is high enough, the service sector workers obtain a higher

\footnotetext{
15 To plot these figures, we have set $\tau_{m}=0.5, \mu_{m}=0.4, \sigma_{m}=4, \mu_{s}=0.4$ and $\sigma_{s}=1.3$.
} 


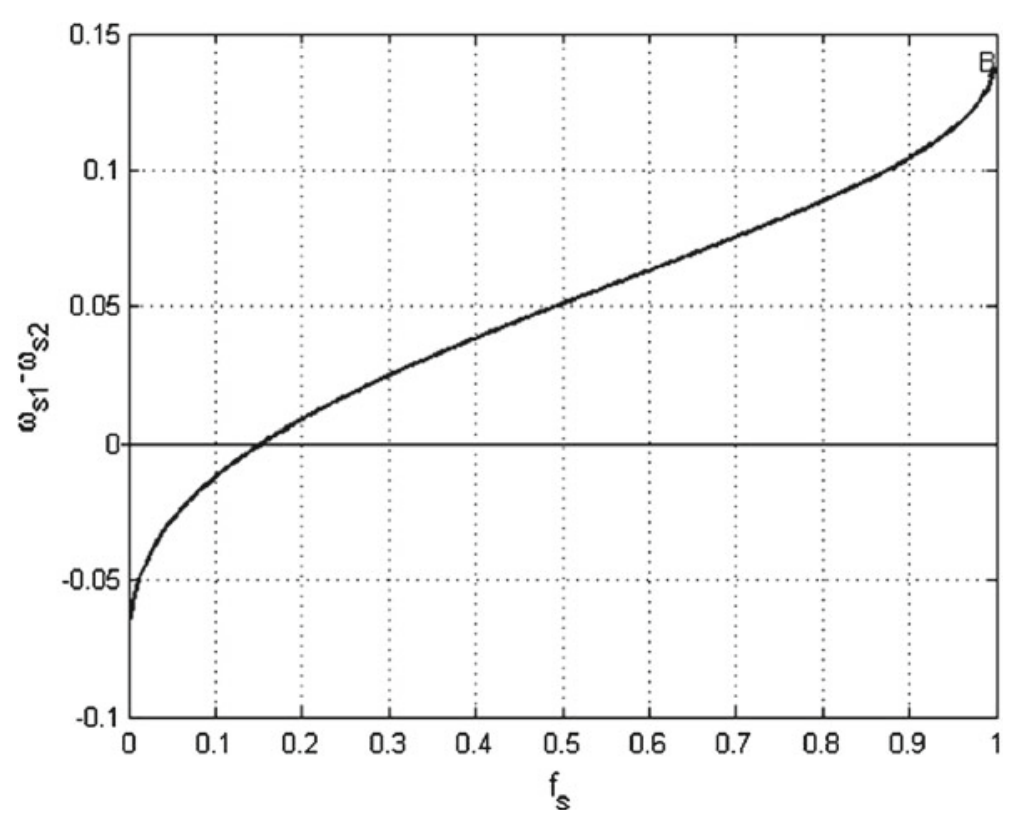

Fig. 3 Agglomeration of services

real wage in region 1 . We conclude that full agglomeration of industry and services is an equilibrium.

From now on, we will assume that $\mu_{s}<\sigma_{s}-1$ ("no black-hole" condition).

\subsection{Full agglomeration of industry and partial agglomeration of services}

Under the "no black-hole" condition, a migration of service workers to a region decreases the attractiveness of this region to the service workers. This effect becomes infinitely strong as the services approach full agglomeration.

Lemma 2 When $\mu_{s}<\sigma_{s}-1$, an increase in the share of services in region $1\left(f_{s}\right)$ decreases the difference between the real wages in the service sector $\left(\omega_{s 1}-\omega_{s 2}\right)$. As the share of services increases from 0 to 1 , the difference between the real wages decreases from $+\infty$ to $-\infty$.

Therefore, the service sector can never be fully agglomerated in equilibrium. The dispersion forces would be infinitely strong. What is possible is the full agglomeration of industry together with partial agglomeration of services.

Full agglomeration of industrial activity in region 1 with partial agglomeration of the service activity in the same region is an equilibrium if, with $\left(f_{s}^{*}, f_{m}^{*}\right)=(s, 1)$, where $s \in\left(\frac{1}{2}, 1\right)$ : the real wages in the industrial sector are higher in region $1\left(\omega_{m 1}>\omega_{m 2}\right)$; the real wages in the service sector are equal across regions $\left(\omega_{s 1}=\omega_{s 2}\right)$; and a small migration of service sector workers to region 1 makes region 2 become more attractive than region 1 to these workers, inducing their return $\left(\frac{\partial\left(\omega_{s 1}-\omega_{s 2}\right)}{\partial f_{s}}<0\right)$. 


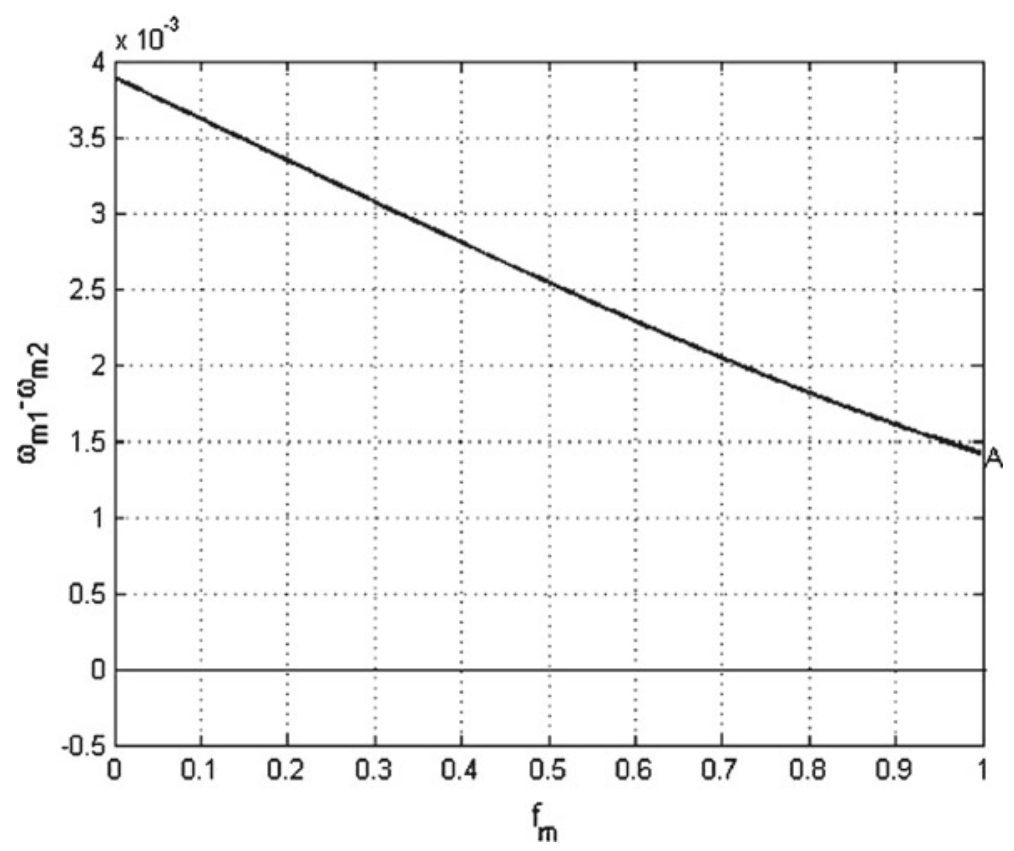

Fig. 4 Agglomeration of industry

The following lemma describes the conditions for the existence of such an equilibrium.

Lemma 3 Full agglomeration of industrial activity in region 1 or 2 and partial agglomeration of the service activity in the same region is an equilibrium if $\mu_{s}<\sigma_{s}-1$ and

$$
\left[\frac{\sigma_{m}\left(1-\frac{\mu_{s}}{\sigma_{s}}\right)-\mu_{m}}{\sigma_{m}\left(1-\frac{\mu_{s}}{\sigma_{s}}\right)+\mu_{m}}\right]^{\frac{\mu_{s}}{\mu_{s}+1-\sigma_{s}}} \phi_{m}^{1-\frac{\mu_{m}\left(\sigma_{s}-1\right)}{\left(\sigma_{m}-1\right)\left(\sigma_{s}-1-\mu_{s}\right)}}-\frac{\phi_{m}^{2}\left[\sigma_{s}\left(1+\frac{\mu_{m}}{\sigma_{m}}\right)-\mu_{s}\right]+\sigma_{s}\left(1-\frac{\mu_{m}}{\sigma_{m}}\right)-\mu_{s}}{2\left(\sigma_{s}-\mu_{s}\right)}>0 .
$$

Figures 4 and 5 illustrate an equilibrium with full agglomeration of industry and partial agglomeration of services. ${ }^{16}$ With $f_{s}=0.586$, we can see from Fig. 4 that the real wage of the industrial workers is always higher in region 1 . Thus, industrial workers locate in region 1. In Fig. 5, we assume that all the industrial activity is concentrated in region $1, f_{m}=1$, and study how the spatial distribution of the service sector activity affects the difference between the real wages of the service sector workers across regions. The migration of the service sector workers leads to an equilibrium with $f_{s}=0.586$, as the real wages of the service sector workers coincide. We conclude that the full agglomeration of industry in region 1 and the partial agglomeration of services (58.6\% in region 1) constitutes an equilibrium.

\footnotetext{
$\overline{16}$ To plot these figures, we have set $\tau_{m}=0.825, \mu_{m}=0.4, \sigma_{m}=4, \mu_{s}=0.4$ and $\sigma_{s}=4$. We have also set $f_{s}=0.586$ in Fig. 4 and $f_{m}=1$ in Fig. 5 .
} 


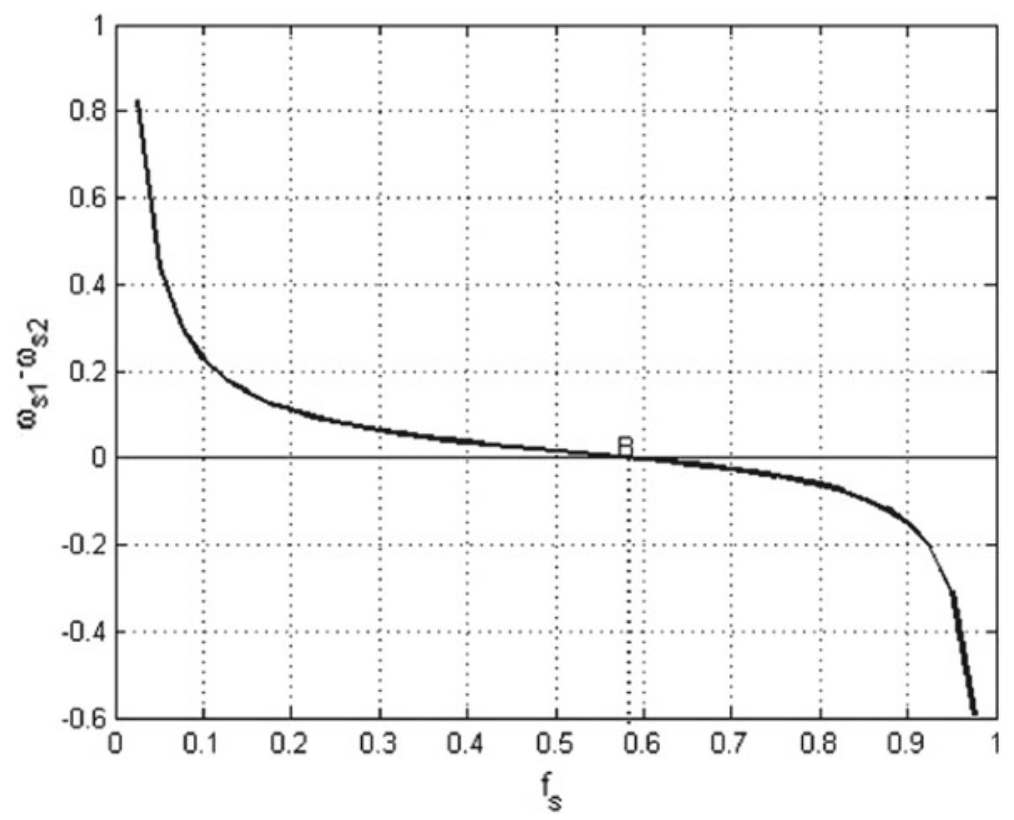

Fig. 5 Partial agglomeration of services

One of the central messages of the new economic geography literature is that there is full agglomeration of industry if the trade costs are sufficiently small. In the model of Forslid and Ottaviano (2003), that we extend, full agglomeration of industry occurs if: $2 \phi_{m}^{1-\frac{\mu_{m}}{\sigma_{m}-1}}>\phi_{m}^{2}\left(1+\frac{\mu_{m}}{\sigma_{m}}\right)+1-\frac{\mu_{m}}{\sigma_{m}}$. Of course, we also obtain this expression when $\mu_{s}=0$ (absence of a service sector). The incorporation of a service sector that is mobile across regions preserves this property of the model, since there is a mutual attraction between the two sectors, which is an additional incentive for industrial firms and workers to remain at the core.

To understand this mutual attraction, observe that the agglomeration forces at work are urbanization economies: workers in both sectors enjoy the availability of greater varieties of services and of locally produced industrial goods ("cost-of-living" effect); and firms enjoy having a greater local market ("home-market" effect), which is constituted by all types of workers. On the other hand, the dispersion force ("marketcrowding" effect) only generates localization diseconomies because there is no competition between industrial and service sector firms, neither in the product markets nor in the labor markets.

In the literature (Helpman 1998; Südekum 2006; Pflüger and Südekum 2008), services typically act as a dispersion force because the service sector is assumed to be fixed (housing). An increase in the industrial activity leads to an increase in the price of housing. This mitigates the tendency for agglomeration. Here, under the assumption that the service sector is mobile across regions, we arrive at the opposite conclusion.

In our model, the service sector is mobile across regions and, therefore, either becomes fully agglomerated together with the industrial sector (if and only if the 
"black-hole" condition holds) or partially agglomerated in the region where there is more industry.

Lemma 4 The following configurations are never an equilibrium:

(i) agglomeration of each sector in different regions;

(ii) symmetric dispersion of services and agglomeration of industry;

(iii) agglomeration of services together with dispersion of industry.

The configurations (i) and (iii) are never an equilibrium because no industrial worker is willing to remain in a region without services. Configuration (ii) cannot be an equilibrium because the service sector workers would be attracted by the region in which industry is agglomerated.

\subsection{Symmetric dispersion of industry and services}

It is also possible to have a symmetric dispersion of economic activity, as in the classical model when the trade costs are high.

Symmetric dispersion of the industrial and service activity, $\left(f_{s}^{*}, f_{m}^{*}\right)=(0.5,0.5)$, is an equilibrium if: the real wages are the same in both regions $\left(\omega_{s 1}=\omega_{s 2}\right.$ and $\left.\omega_{m 1}=\omega_{m 2}\right)$; and if a small migration of both kinds of workers generates a difference between real wages that induces the workers to return to their original locations.

This last condition is verified if and only if, at $\left(f_{s}^{*}, f_{m}^{*}\right)=(0.5,0.5)$, we have $\operatorname{det}(J)>0$ and $\operatorname{tr}(J)<0$, where $J$ is the Jacobian matrix obtained from expressions (41) and (43):

$$
J=\left[\begin{array}{ll}
\frac{\partial\left(\omega_{m 1}-\omega_{m 2}\right)}{\partial f_{m}} & \frac{\partial\left(\omega_{m 1}-\omega_{m 2}\right)}{\partial f_{s}} \\
\frac{\partial\left(\omega_{s} 1-\omega_{s}\right)}{\partial f_{m}} & \frac{\partial\left(\omega_{s} 1-\omega_{s 2}\right)}{\partial f_{s}}
\end{array}\right] .
$$

By symmetry, at $\left(f_{s}^{*}, f_{m}^{*}\right)=(0.5,0.5)$, we have $\omega_{s 1}=\omega_{s 2}$ and $\omega_{m 1}=\omega_{m 2}$. The only question is whether this spatial configuration is stable.

We know, from Lemma 2, that a migration of service sector workers generates incentives for their return, i.e., $\frac{\partial\left(\omega_{s 1}-\omega_{s 2}\right)}{\partial f_{s}}<0$. This contributes to the stability of symmetric dispersion.

On the other hand, a migration of service sector workers generates incentives for the industrial sector workers to follow them, because of the resulting wider supply of services.

Lemma 5 When $\left(f_{s}, f_{m}\right)=(0.5,0.5)$, the migration of service sector workers to region 1 increases the difference between the real wages of the industrial sector workers in region 1 and region 2 , that is, $\frac{\partial\left(\omega_{m 1}-\omega_{m 2}\right)}{\partial f_{s}}>0$.

The converse is also true, for the same economic reason. A migration of industrial workers generates incentives for the service sector workers to follow them.

Lemma 6 When $\left(f_{s}, f_{m}\right)=(0.5,0.5)$, the migration of industrial sector workers to region 1 increases the difference between the real wages of the service sector workers in region 1 and region 2 , that is, $\frac{\partial\left(\omega_{s 1}-\omega_{s 2}\right)}{\partial f_{m}}>0$. 


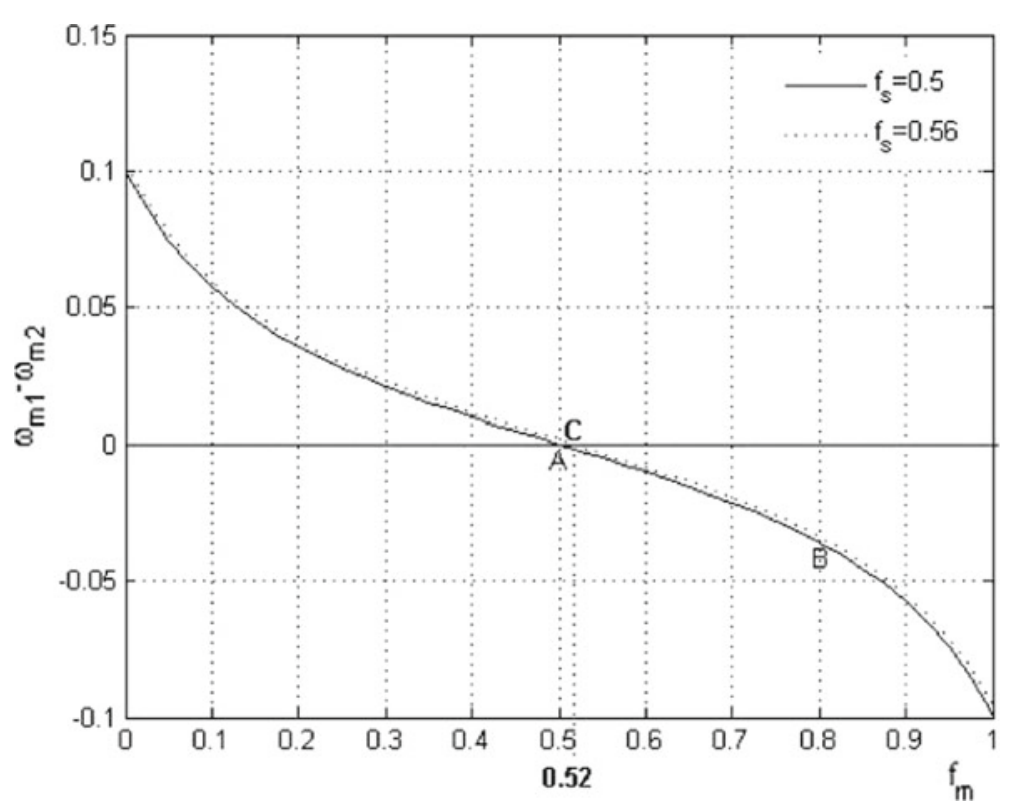

Fig. 6 Dispersion of industry

Stability depends on the relative strength of the four effects that define the Jacobian matrix. The following figures are useful for an intuitive understanding of the dynamics. $^{17}$

Assume that the economy is initially located in point $\mathrm{A}$, with $\left(f_{s}, f_{m}\right)=(0.5,0.5)$. We have $\omega_{m 1}=\omega_{m 2}$ (Fig. 6) and $\omega_{s 1}=\omega_{s 2}$ (Fig. 7). Consider an increase in the number of industrial workers in region 1 , to $f_{m}=0.8$ (point B). From Lemma 6 , an increase in $f_{m}$ increases $\omega_{s 1}-\omega_{s 2}$, and thus the curve in Fig. 7 moves up. The service sector workers would tend to move to region 1 , until $f_{s}=0.56$. On the other hand, with $f_{s}=0.56$, the curve in Fig. 6 moves up, and the industrial workers would also migrate, until $f_{m}=0.52$. With $f_{m}=0.52$, the resulting $f_{s}$ would be lower than 0.56 , giving rise to a new $f_{m}$, lower than 0.52 . It seems that this process continues until $\left(f_{s}, f_{m}\right)=(0.5,0.5)$, suggesting that symmetric dispersion is an equilibrium.

We can see from Fig. 8 that dispersion is unstable when $\tau_{m}=0.9 .{ }^{18}$ An increase in $f_{m}$ increases the difference between the real wages of the industrial workers in region 1 and region 2, attracting workers from region 2 to region 1. From Lemma 6, an increase in $f_{m}$ also increases the difference between the real wages in the service sector. Therefore, in the long run, we will have partial agglomeration of the service sector activity and full agglomeration of the industrial activity.

\footnotetext{
17 To plot Figs. 6 and 7, we have set $\mu_{m}=0.4, \sigma_{m}=4, \mu_{s}=0.4, \sigma_{s}=4$ and $\tau_{m}=0.5$.

18 To plot Figs. 8 and 9, we have set $\mu_{m}=0.4 \sigma_{m}=4, \mu_{s}=0.4, \sigma_{s}=4$ and $\tau_{m}=0.9$. Additionally, we have set $f_{s}=0.5$ to plot Fig. 8 and $f_{m}=1$ to plot Fig. 9 .
} 


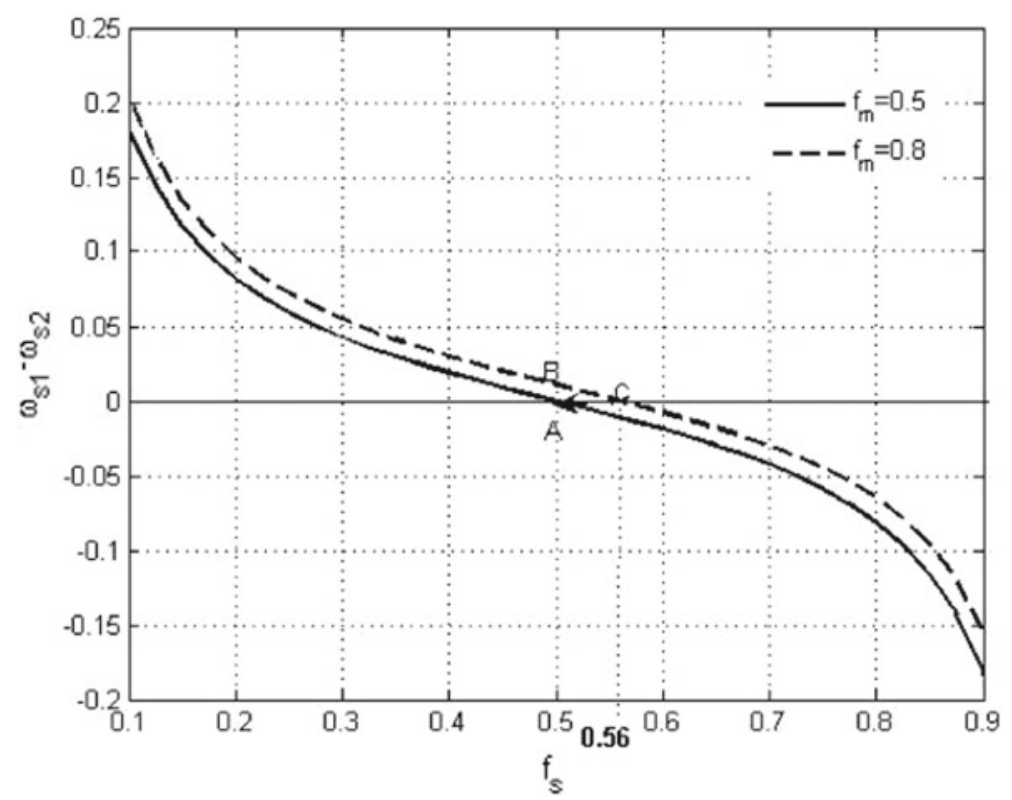

Fig. 7 Dispersion of services

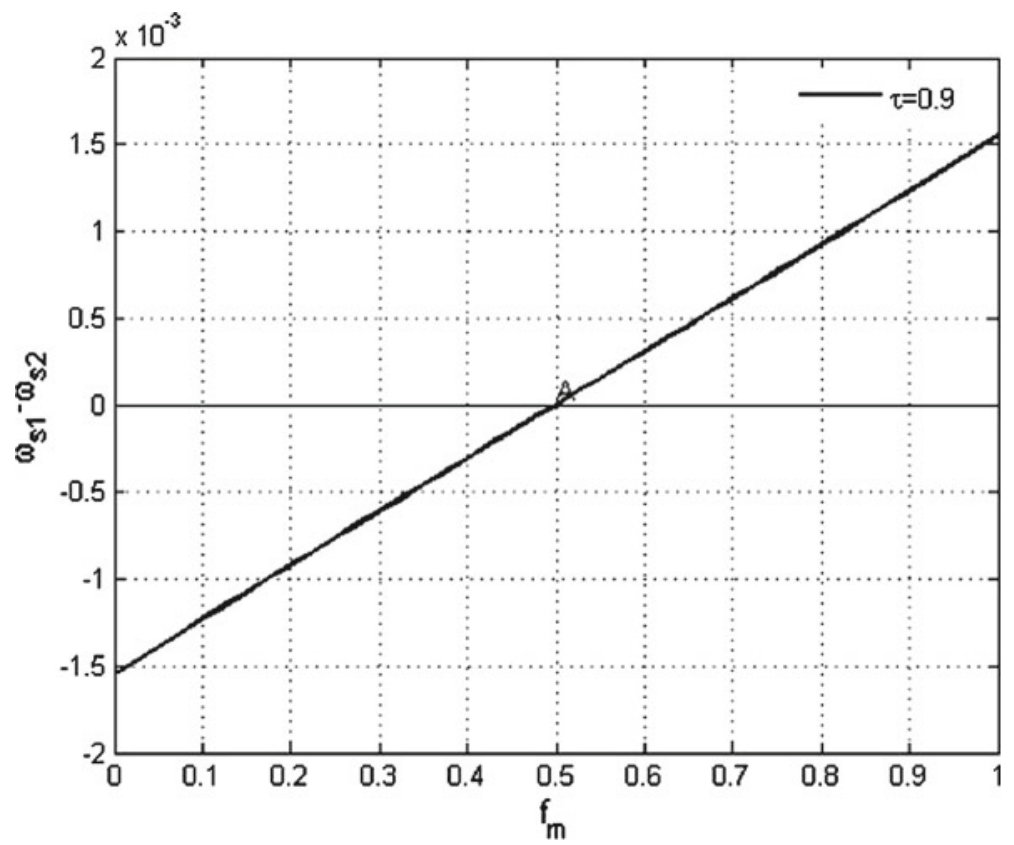

Fig. 8 Dispersion becomes unstable 


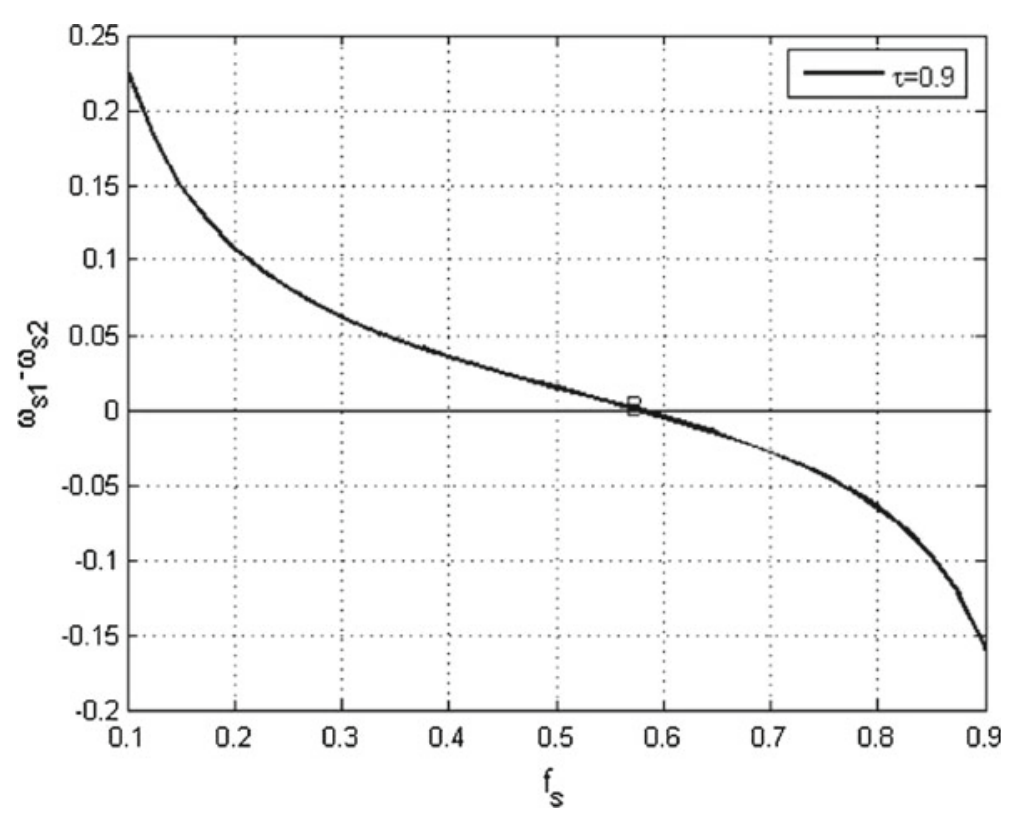

Fig. 9 Asymmetric Dispersion

Figure 10 illustrates a case in which symmetric dispersion of the industrial and service activity is an equilibrium for low values of $\phi_{m} \cdot{ }^{19}$

For the parameter values in our numerical example, $\operatorname{tr}(J)$ is negative for any $\phi_{m} \in$ $(0,1)$. Therefore, the sign of the determinant is crucial for the stability. From Fig. 10, we can see that $\operatorname{det}(J)$ is positive for low values of $\phi_{m}$. This means that the eigenvalues of $J$ have negative real parts, and symmetric dispersion of industry and services is an equilibrium.

For high values of $\phi_{m}$, the symmetric dispersion becomes unstable. In this case, partial agglomeration of the service activity with full agglomeration of the industrial activity in one region becomes the equilibrium.

This result can be viewed in Fig. 11, where we also plot the condition associated with the full agglomeration of industry and partial agglomeration of services (46) as a function of $\phi_{m}$. When $\phi_{m}$ is higher than $\phi_{m}^{*}$, full agglomeration of all industrial activity in one region with partial agglomeration of the service activity becomes an equilibrium. Therefore, point $A$ is a threshold value for $\phi_{m}$.

In particular, when $\sigma_{s}>\mu_{s}+1$, the economy can have two distinct equilibrium configurations. For high trade costs $\left(\right.$ low $\phi_{m}$ ), we find that symmetric dispersion of services and industry is an equilibrium, while for low trade costs (high $\left.\phi_{m}\right)$, we find that full agglomeration of industry with partial agglomeration of services is an equilibrium.

The point is whether small deviations from symmetric dispersion tend to dissipate or to reinforce themselves. Starting from a situation of symmetric dispersion, a small migration of industrial workers is reinforced by the "home-market effect" and

19 In Figs. 10 and 11, it is also assumed that $\sigma_{m}=4, \sigma_{s}=4, \mu_{m}=0.4$ and $\mu_{s}=0.4$. 


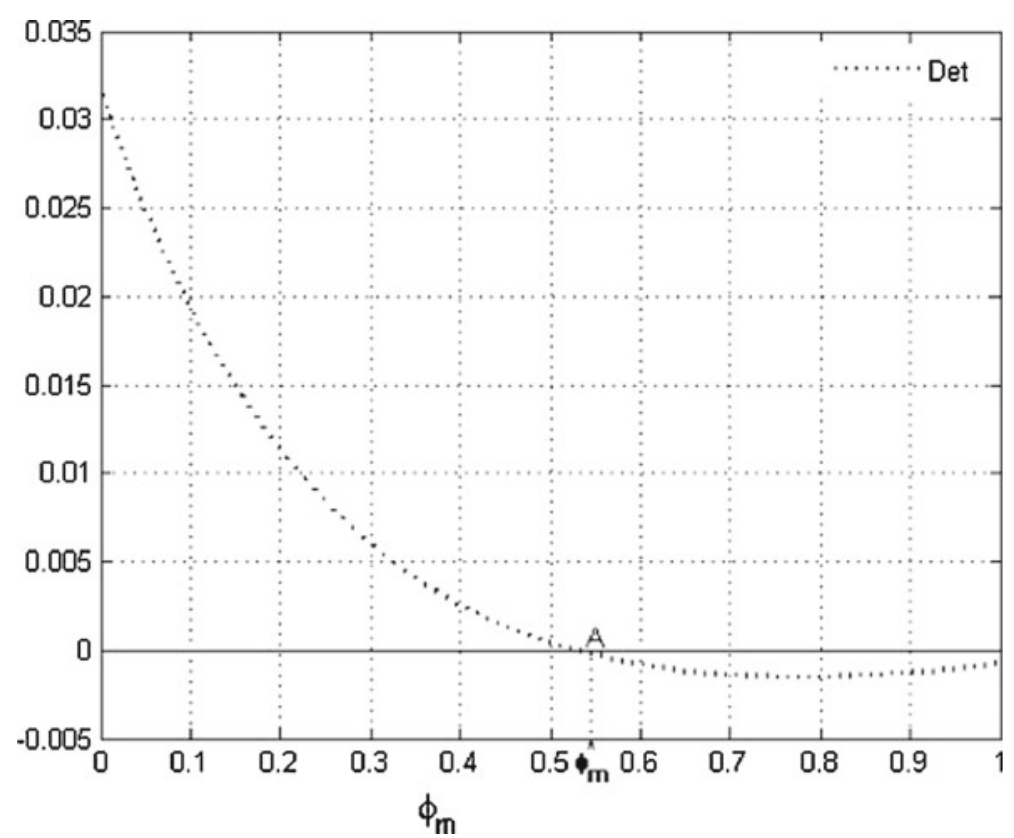

Fig. $10 \operatorname{Det}(J)$ as a function of $\phi_{m}$

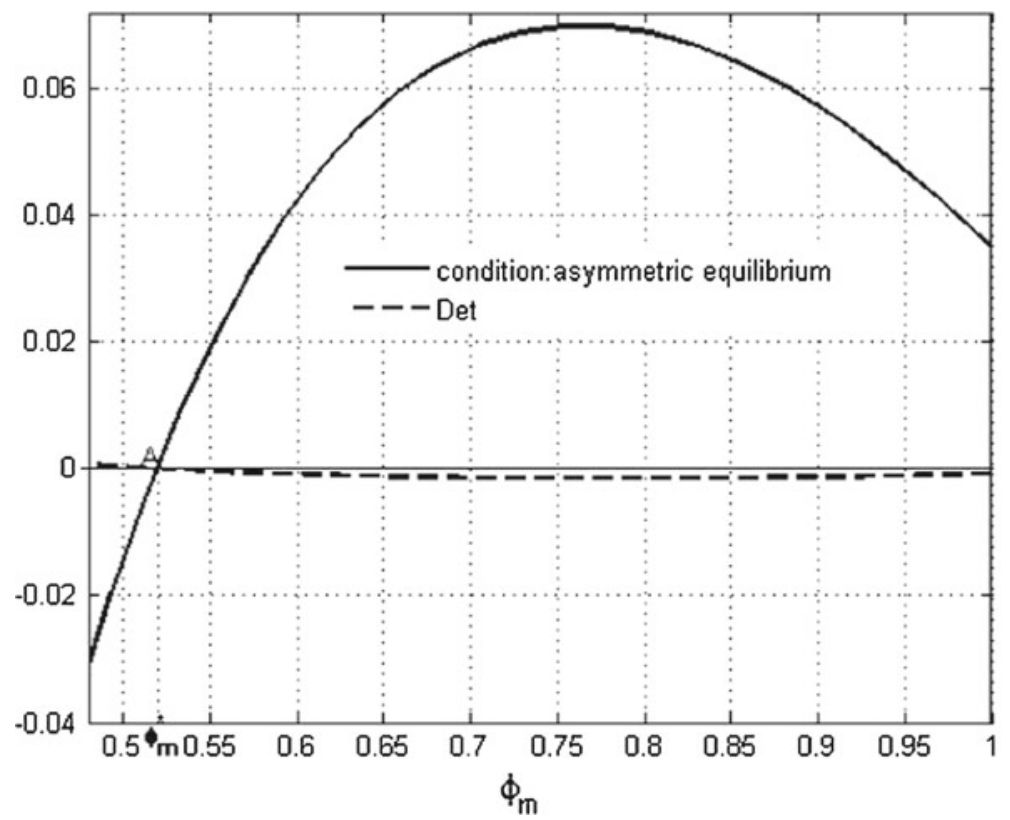

Fig. 11 Threshold value for $\phi_{m}$ 


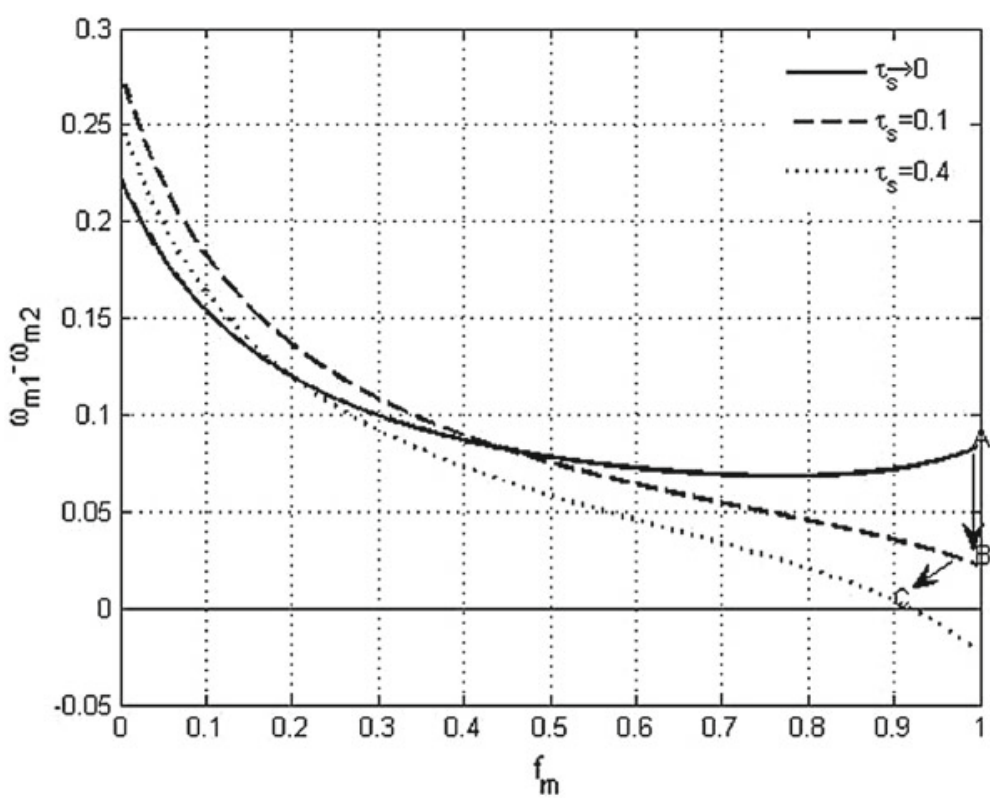

Fig. 12 Industry becomes dispersed

the "cost-of-living" effect. These two effects are strengthened by the fact that there are some service sector workers that follow the industrial sector workers. Symmetric dispersion is an equilibrium if the "market-crowding" effect in the industrial sector is sufficiently strong to overcome these agglomeration forces.

\subsection{The case in which services are tradable}

In this section, we show, numerically, that a different spatial configuration of economic activity, agglomeration of services with dispersion of industry, can appear when services are tradable $\left(0<\phi_{s} \leq \phi_{m}<1\right)$.

Consider an initial equilibrium, in which both industry and services are concentrated in region 1. Figure 12 illustrates how a decrease in the trade cost of services (an increase in $\tau_{s}$ ) affects the spatial distribution of industry when all services are concentrated in region 1 (point A). The main result is that a fall in the trade cost of services leads to an equilibrium in which industry becomes asymmetrically dispersed (point C), while the service sector remains concentrated in region 1 (see Fig. 13). ${ }^{20}$

The same decrease in the trade cost of services (from $\tau_{s} \rightarrow 0$ to $\tau_{s}=0.4$ ) may not change the initial equilibrium configuration, being compatible with symmetric dispersion of both sectors (set $\tau_{m}=0.5$, keeping fixed the remaining parameters) or partial agglomeration of services with full agglomeration of industry (set $\tau_{m}=0.825$ ).

\footnotetext{
20 To plot Figs. 12 and 13, we have set $\tau_{m}=0.5, \mu_{m}=0.4, \sigma_{m}=4, \mu_{s}=0.4, \sigma_{s}=1.3$. We also set $f_{s}=1$ in Fig. 12 and $f_{m}=1$ in Fig. 13.
} 


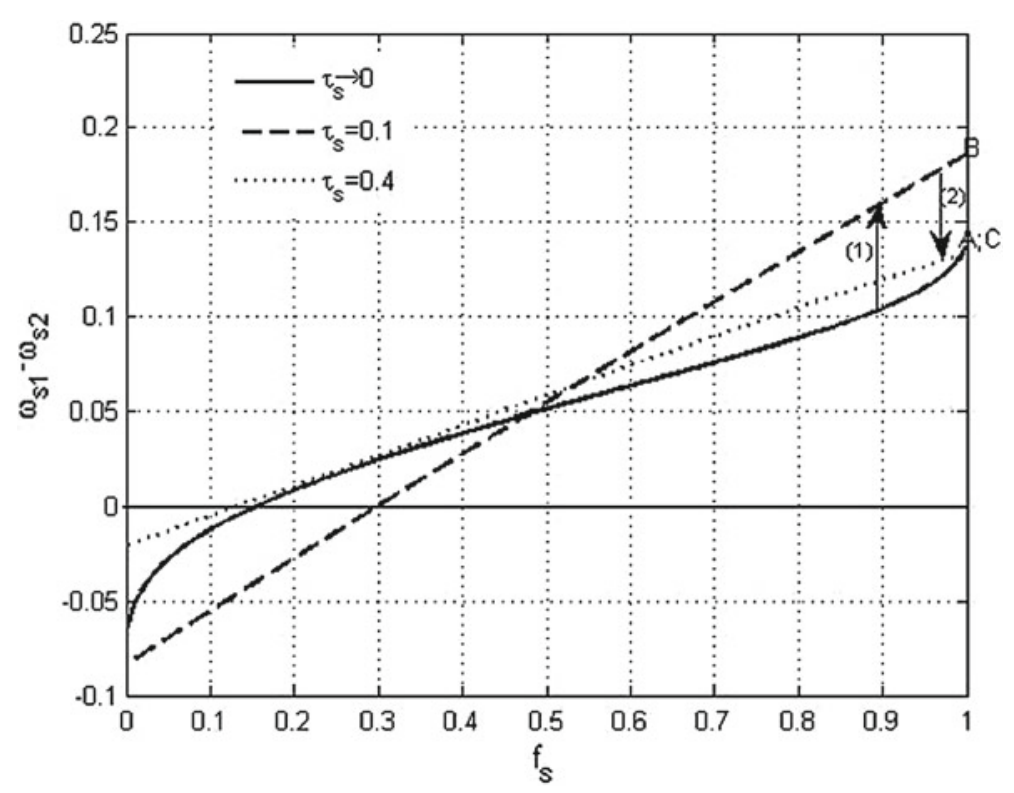

Fig. 13 Agglomeration of services

\section{Conclusion}

We have extended the footloose entrepreneur model (Forslid and Ottaviano 2003) to allow for a third sector: a monopolistic competitive sector of non-tradable goods (services).

We find that the strength of the preference for variety of services is crucial to explain the spatial distribution of the industrial and service activities. When the elasticity of substitution among services is below a certain threshold, full agglomeration of industry and services in a single region is always an equilibrium. But, this threshold value for the elasticity of substitution among services seems a bit too low to be attainable in modern economies, as it corresponds to a very high price markup over marginal cost. ${ }^{21}$ Based on this model, we should not expect, therefore, full agglomeration of industry and services in a single region.

With a higher elasticity of substitution among services, which is more likely, the spatial distribution of economic activity depends on the trade costs in the industrial sector. If these trade costs are high, symmetric dispersion of the services and industrial activity is an equilibrium. If they are low, full agglomeration of industry with partial agglomeration of services in the same region is an equilibrium (the industrialized region has more than $50 \%$ of the service sector activity).

$\overline{21 \text { With services representing } 50} \%$ of the economic activity $\left(\mu_{s}=0.5\right)$, at this threshold $\left(\sigma_{s}=1+\mu_{s}\right)$, we obtain $p_{s}=\frac{\sigma_{s}}{\sigma_{s}-1} \beta=3 \beta$ (the price of a representative service is equal to 3 times the marginal cost). A lower price markup is obtained if we consider a higher elasticity of substitution among services. 
The critical value of the trade costs above which agglomeration does not take place should be higher in the presence of a non-tradable goods sector. This is because the partial agglomeration of services in the core is an additional force that is contrary to the dispersion of economic activity.

It is clear that an increase in the size of the service sector reduces the regional price indices, thus increasing the welfare of the region. This, however, is a crude statement about policy implications and welfare concerns. A deeper understanding is out of the scope of this paper but is a relevant issue for future research.

Taking into account the existence of non-tradable goods, with specialized workers that are mobile across regions, should provide new insights into the determinants of the spatial organization of economic activity. We hope that this model may be seen as a step in this direction.

Acknowledgments We are grateful to Alper Çenesiz, Pascal Mossay, Diego Puga, and seminar participants at U. Vigo and U. Porto for useful comments. We also thank three anonymous referees who have made many suggestions that allowed us to improve this paper substantially. The authors acknowledge support from FCT and FEDER (research grant PTDC/EGE-ECO/108331/2008). Vasco Leite acknowledges support from FCT (Ph.D. scholarship). Sofia Castro acknowledges support from Centro de Matemáatica da Universidade do Porto, financed by FCT through the programmes POCTI and POSI. João Correiada-Silva acknowledges support from CEF.UP.

\section{Appendix}

\section{Short-run equilibrium}

The nominal wages of the industrial and service sector workers are:

$$
\begin{aligned}
W_{m i} & =\frac{\mu_{m}}{\sigma_{m}}\left(\frac{Y_{i}}{M_{i}+\phi_{m} M_{j}}+\frac{Y_{j} \phi_{m}}{\phi_{m} M_{i}+M_{j}}\right), \\
W_{s i} & =\frac{\mu_{s}}{\sigma_{s}}\left(\frac{Y_{i}}{S_{i}+\phi_{s} S_{j}}+\frac{Y_{j} \phi_{s}}{\phi_{s} S_{i}+S_{j}}\right) .
\end{aligned}
$$

The regional nominal incomes are:

$$
Y_{i}=\frac{1-M-S}{2}+W_{m i} M_{i}+W_{s i} S_{i}
$$

Our goal in this section is to find $W_{m i}$ and $W_{s i}$ as functions of the parameters of the model. First, we determine $Y_{i}$ and $Y_{j}$. Then, we substitute these into $W_{m i}$ and $W_{s i}$.

Substituting (24) and (25) in (26) and using $a=\frac{1-M-S}{2}$, we obtain:

$$
\begin{aligned}
Y_{i}= & a+M_{i} \frac{\mu_{m}}{\sigma_{m}}\left(\frac{Y_{i}}{M_{i}+\phi_{m} M_{j}}+\frac{Y_{j} \phi_{m}}{\phi_{m} M_{i}+M_{j}}\right) \\
& +S_{i} \frac{\mu_{s}}{\sigma_{s}}\left(\frac{Y_{i}}{S_{i}+\phi_{s} S_{j}}+\frac{Y_{j} \phi_{s}}{\phi_{s} S_{i}+S_{j}}\right) .
\end{aligned}
$$


Rearranging, we obtain $Y_{i}$ as a function of $Y_{j}$ :

$$
\begin{aligned}
& Y_{i}\left[1-\frac{\mu_{m} M_{i}}{\sigma_{m}\left(M_{i}+\phi_{m} M_{j}\right)}-\frac{\mu_{s} S_{i}}{\sigma_{s}\left(S_{i}+\phi_{s} S_{j}\right)}\right] \\
& \quad=a+\left[\frac{\mu_{m} M_{i} \phi_{m}}{\sigma_{m}\left(\phi_{m} M_{i}+M_{j}\right)}+\frac{\mu_{s} S_{i} \phi_{s}}{\sigma_{s}\left(\phi_{s} S_{i}+S_{j}\right)}\right] Y_{j} .
\end{aligned}
$$

For convenience, define:

$$
\begin{aligned}
b_{m} & =\phi_{m} M_{i}+M_{j}, \\
c_{m} & =M_{i}+\phi_{m} M_{j}, \\
b_{s} & =\phi_{s} S_{i}+S_{j}, \\
c_{s} & =S_{i}+\phi_{s} S_{j} .
\end{aligned}
$$

With some manipulation, we obtain:

$$
Y_{i} \frac{\sigma_{m} c_{m} \sigma_{s} c_{s}-\mu_{m} M_{i} \sigma_{s} c_{s}-\mu_{s} S_{i} \sigma_{m} c_{m}}{\sigma_{m} c_{m} \sigma_{s} c_{s}}=a+\frac{\mu_{m} M_{i} \phi_{m} \sigma_{s} b_{s}+\mu_{s} S_{i} \phi_{s} \sigma_{m} b_{m}}{\sigma_{s} b_{s} \sigma_{m} b_{m}} Y_{j}
$$

Which is equivalent to:

$$
Y_{i}=\frac{a \sigma_{m} \sigma_{s} c_{m} c_{s}+\left(\mu_{m} M_{i} \phi_{m} \sigma_{s} b_{s}+S_{i} \mu_{s} \phi_{s} \sigma_{m} b_{m}\right) c_{m} c_{s} b_{m}^{-1} b_{s}^{-1} Y_{j}}{\sigma_{m} c_{m}\left(\sigma_{s} c_{s}-S_{i} \mu_{s}\right)-M_{i} \mu_{m} \sigma_{s} c_{s}}
$$

The above equation yields $Y_{i}$ as a function of $Y_{j}$. By symmetry, we can write $Y_{j}$ as function of $Y_{i}$ as follows:

$$
Y_{j}=\frac{a \sigma_{m} \sigma_{s} b_{m} b_{s}+\left(\mu_{m} M_{j} \phi_{m} \sigma_{s} c_{s}+S_{j} \mu_{s} \phi_{s} \sigma_{m} c_{m}\right) b_{m} b_{s} c_{m}^{-1} c_{s}^{-1} Y_{i}}{\sigma_{m} b_{m}\left(\sigma_{s} b_{s}-S_{j} \mu_{s}\right)-M_{j} \mu_{m} \sigma_{s} b_{s}} .
$$

Substituting (28) in (27) and simplifying, we obtain:

$$
Y_{i}=\frac{c_{m} c_{s}\left[\sigma_{m} b_{m}\left(\sigma_{s} b_{s}-S_{j} \mu_{s}\right)-M_{j} \mu_{m} \sigma_{s} b_{s}+M_{i} \mu_{m} \phi_{m} \sigma_{s} b_{s}+S_{i} \mu_{s} \phi_{s} \sigma_{m} b_{m}\right]}{a^{-1} \sigma_{m}^{-1} \sigma_{s}^{-1} R},
$$

and, by symmetry,

$$
Y_{j}=\frac{b_{m} b_{s}\left[\sigma_{m} c_{m}\left(\sigma_{s} c_{s}-S_{i} \mu_{s}\right)-M_{i} \mu_{m} \sigma_{s} c_{s}+M_{j} \mu_{m} \phi_{m} \sigma_{s} c_{s}+S_{j} \mu_{s} \phi_{s} \sigma_{m} c_{m}\right]}{a^{-1} \sigma_{m}^{-1} \sigma_{s}^{-1} R},
$$


where

$$
\begin{aligned}
R= & {\left[\sigma_{m} c_{m}\left(\sigma_{s} c_{s}-S_{i} \mu_{s}\right)-M_{i} \mu_{m} \sigma_{s} c_{s}\right]\left[\sigma_{m} b_{m}\left(\sigma_{s} b_{s}-S_{j} \mu_{s}\right)-M_{j} \mu_{m} \sigma_{s} b_{s}\right] } \\
& -\left(M_{i} \mu_{m} \phi_{m} \sigma_{s} b_{s}+S_{i} \mu_{s} \phi_{s} \sigma_{m} b_{m}\right)\left(M_{j} \mu_{m} \phi_{m} \sigma_{s} c_{s}+S_{j} \mu_{s} \phi_{s} \sigma_{m} c_{m}\right) .
\end{aligned}
$$

Denoting by $Y_{i}^{N}$ and $Y_{j}^{N}$ the numerators of $Y_{i}$ and $Y_{j}$ in Eqs. (29) and (30), we can rewrite (24) in the following way:

$$
W_{m i}=\frac{\mu_{m} \sigma_{s} a}{c_{m} b_{m} R}\left(Y_{i}^{N} b_{m}+\phi_{m} Y_{j}^{N} c_{m}\right)
$$

Replacing the expressions for $Y_{i}$ and $Y_{j}$, and setting $i=1$ and $j=2$, we obtain:

$$
\begin{aligned}
W_{m 1}= & \frac{\mu_{m} a \sigma_{m} \sigma_{s}}{R}\left[c_{s} b_{m}\left(\sigma_{s} b_{s}-S_{2} \mu_{s}\right)-M_{2} c_{s} \sigma_{m}^{-1} \mu_{m} \sigma_{s} b_{s}+M_{1} c_{s} \sigma_{m}^{-1} \mu_{m} \phi_{m} \sigma_{s} b_{s}\right. \\
& +S_{1} \mu_{s} \phi_{s} c_{s} b_{m}+\phi_{m} b_{s} c_{m}\left(\sigma_{s} c_{s}-S_{1} \mu_{s}\right)-M_{1} \phi_{m} b_{s} \mu_{m} \sigma_{s} \sigma_{m}^{-1} c_{s} \\
& \left.+M_{2} \phi_{m}^{2} b_{s} \mu_{m} \sigma_{s} \sigma_{m}^{-1} c_{s}+S_{2} \phi_{m} b_{s} \mu_{s} \phi_{s} c_{m}\right] .
\end{aligned}
$$

Denoting $\bar{C}=\frac{\mu_{m} c_{s} b_{s} \sigma_{s} a}{R}$, and replacing $b_{m}, c_{m}, b_{s}$, and $c_{s}$ by the corresponding expressions:

$$
\begin{aligned}
\frac{W_{m 1}}{\bar{C}}= & \sigma_{m}\left(\phi_{m} M_{1}+M_{2}\right)\left(\sigma_{s}-\mu_{s} \frac{S_{2}-\phi_{s} S_{1}}{S_{2}+\phi_{s} S_{1}}\right)+\mu_{m} \sigma_{s}\left(\phi_{m} M_{1}-M_{2}\right) \\
& +\phi_{m}\left[\sigma_{m}\left(M_{1}+\phi_{m} M_{2}\right)\left(\sigma_{s}-\mu_{s} \frac{S_{1}-\phi_{s} S_{2}}{S_{1}+\phi_{s} S_{2}}\right)+\mu_{m} \sigma_{s}\left(\phi_{m} M_{2}-M_{1}\right)\right] .
\end{aligned}
$$

Manipulating:

$$
\begin{aligned}
& \frac{W_{m 1}}{\bar{C}}=\phi_{m} \sigma_{m} M_{1}\left[2 \sigma_{s}-\mu_{s}\left(\frac{S_{2}-\phi_{s} S_{1}}{S_{2}+\phi_{s} S_{1}}+\frac{S_{1}-\phi_{s} S_{2}}{S_{1}+\phi_{s} S_{2}}\right)\right] \\
& +M_{2}\left[\sigma_{m} \sigma_{s}\left(\phi_{m}^{2}+1\right)+\sigma_{s} \mu_{m}\left(\phi_{m}^{2}-1\right)-\sigma_{m} \mu_{s}\left(\phi_{m}^{2} \frac{S_{1}-\phi_{s} S_{2}}{S_{1}+\phi_{s} S_{2}}+\frac{S_{2}-\phi_{s} S_{1}}{S_{2}+\phi_{s} S_{1}}\right)\right] .
\end{aligned}
$$

It is easy to show that:

$$
\frac{S_{2}-\phi_{s} S_{1}}{\phi_{s} S_{1}+S_{2}}+\frac{S_{1}-\phi_{s} S_{2}}{S_{1}+\phi_{s} S_{2}}=\frac{2 S_{1} S_{2}\left(1-\phi_{s}^{2}\right)}{S_{1} S_{2}\left(1+\phi_{s}^{2}\right)+\phi_{s}\left(S_{1}^{2}+S_{2}^{2}\right)} .
$$


Substituting this expression, we determine $W_{m 1}$ and (by symmetry) $W_{m 2}$. The nominal wages in the service sector are also obtained, by analogy:

$$
\begin{aligned}
W_{m 1}= & \bar{C} \sigma_{m} 2 \phi_{m} M_{1}\left[\sigma_{s}-\mu_{s} \frac{S_{1} S_{2}\left(1-\phi_{s}^{2}\right)}{S_{1} S_{2}\left(1+\phi_{s}^{2}\right)+\phi_{s}\left(S_{1}^{2}+S_{2}^{2}\right)}\right] \\
& +\bar{C} \sigma_{m} M_{2}\left\{\sigma_{s}\left[\phi_{m}^{2}+1+\frac{\mu_{m}}{\sigma_{m}}\left(\phi_{m}^{2}-1\right)\right]-\mu_{s}\left(\phi_{m}^{2} \frac{S_{1}-\phi_{s} S_{2}}{S_{1}+\phi_{s} S_{2}}+\frac{S_{2}-\phi_{s} S_{1}}{\phi_{s} S_{1}+S_{2}}\right)\right\}, \\
W_{m 2}= & \bar{C} \sigma_{m} 2 \phi_{m} M_{2}\left[\sigma_{s}-\mu_{s} \frac{S_{1} S_{2}\left(1-\phi_{s}^{2}\right)}{S_{1} S_{2}\left(1+\phi_{s}^{2}\right)+\phi_{s}\left(S_{1}^{2}+S_{2}^{2}\right)}\right] \\
& +\bar{C} \sigma_{m} M_{1}\left\{\sigma_{s}\left[\phi_{m}^{2}+1+\frac{\mu_{m}}{\sigma_{m}}\left(\phi_{m}^{2}-1\right)\right]-\mu_{s}\left(\phi_{m}^{2} \frac{S_{2}-\phi_{s} S_{1}}{\phi_{s} S_{1}+S_{2}}+\frac{S_{1}-\phi_{s} S_{2}}{S_{1}+\phi_{s} S_{2}}\right)\right\}, \\
W_{s 1}= & \bar{D} \sigma_{s} 2 \phi_{s} S_{1}\left[\sigma_{m}-\mu_{m} \frac{M_{1} M_{2}\left(1-\phi_{m}^{2}\right)}{M_{1} M_{2}\left(1+\phi_{m}^{2}\right)+\phi_{m}\left(M_{1}^{2}+M_{2}^{2}\right)}\right] \\
& +\bar{D} \sigma_{s} S_{2}\left\{\sigma_{m}\left[\phi_{s}^{2}+1+\frac{\mu_{s}}{\sigma_{s}}\left(\phi_{s}^{2}-1\right)\right]-\mu_{m}\left(\phi_{s}^{2} \frac{M_{1}-\phi_{m} M_{2}}{M_{1}+\phi_{m} M_{2}}+\frac{M_{2}-\phi_{m} M_{1}}{\phi_{m} M_{1}+M_{2}}\right)\right\}, \\
W_{s 2}= & \bar{D} \sigma_{s} 2 \phi_{s} S_{2}\left[\sigma_{m}-\mu_{m} \frac{M_{1} M_{2}\left(1-\phi_{m}^{2}\right)}{M_{1} M_{2}\left(1+\phi_{m}^{2}\right)+\phi_{m}\left(M_{1}^{2}+M_{2}^{2}\right)}\right] \\
& +\bar{D} \sigma_{s} S_{1}\left\{\sigma_{m}\left[\phi_{s}^{2}+1+\frac{\mu_{s}}{\sigma_{s}}\left(\phi_{s}^{2}-1\right)\right]-\mu_{m}\left(\phi_{s}^{2} \frac{M_{2}-M_{1} \phi_{m}}{\phi_{m} M_{1}+M_{2}}+\frac{M_{1}-\phi_{m} M_{2}}{M_{1}+\phi_{m} M_{2}}\right)\right\},
\end{aligned}
$$

where

$$
\begin{aligned}
& \bar{C}=\frac{\mu_{m} \sigma_{s} \frac{1-M-S}{2}\left(S_{1}+\phi_{s} S_{2}\right)\left(\phi_{s} S_{1}+S_{2}\right)}{R}, \\
& \bar{D}=\frac{\mu_{s} \sigma_{m} \frac{1-M-S}{2}\left(M_{1}+\phi_{m} M_{2}\right)\left(\phi_{m} M_{1}+M_{2}\right)}{R},
\end{aligned}
$$

and

$$
\begin{aligned}
R= & \left\{\sigma_{m}\left(M_{1}+\phi_{m} M_{2}\right)\left[\sigma_{s}\left(S_{1}+\phi_{s} S_{2}\right)-S_{1} \mu_{s}\right]-M_{1} \mu_{m} \sigma_{s}\left(S_{1}+\phi_{s} S_{2}\right)\right\} \\
& \times\left\{\sigma_{m}\left(\phi_{m} M_{1}+M_{2}\right)\left[\sigma_{s}\left(\phi_{s} S_{1}+S_{2}\right)-S_{2} \mu_{s}\right]-M_{2} \mu_{m} \sigma_{s}\left(\phi_{s} S_{1}+S_{2}\right)\right\} \\
& -\left[M_{1} \mu_{m} \phi_{m} \sigma_{s}\left(\phi_{s} S_{1}+S_{2}\right)+S_{1} \mu_{s} \phi_{s} \sigma_{m}\left(\phi_{m} M_{1}+M_{2}\right)\right] \\
& \times\left[M_{2} \mu_{m} \phi_{m} \sigma_{s}\left(S_{1}+\phi_{s} S_{2}\right)+S_{2} \mu_{s} \phi_{s} \sigma_{m}\left(M_{1}+\phi_{m} M_{2}\right)\right] .
\end{aligned}
$$

Short-run equilibrium with $\tau_{s} \rightarrow 0$

With $\tau_{s} \rightarrow$ 0, Eqs. (1), (18), (21)-(23) become:

$$
\begin{aligned}
& W_{m 1}=\frac{\mu_{m}}{\sigma_{m} M}\left[\frac{Y_{1}}{f_{m}+\phi_{m}\left(1-f_{m}\right)}+\frac{\phi_{m} Y_{2}}{\phi_{m} f_{m}+1-f_{m}}\right], \\
& W_{m 2}=\frac{\mu_{m}}{\sigma_{m} M}\left[\frac{Y_{2}}{1-f_{m}+\phi_{m} f_{m}}+\frac{\phi_{m} Y_{1}}{\phi_{m}\left(1-f_{m}\right)+f_{m}}\right],
\end{aligned}
$$




$$
\begin{aligned}
& W_{s 1}=\frac{\mu_{s} Y_{1}}{\sigma_{s} S f_{s}}, \\
& W_{s 2}=\frac{\mu_{s} Y_{2}}{\sigma_{s} S\left(1-f_{s}\right)}, \\
& Y_{1}=\frac{1-M-S}{2}+W_{m 1} M f_{m}+W_{s 1} S f_{s}, \\
& Y_{2}=\frac{1-M-S}{2}+W_{m 2} M\left(1-f_{m}\right)+W_{s 2} S\left(1-f_{s}\right), \\
& P_{1}=\rho\left[f_{m}+\left(1-f_{m}\right) \phi_{m}\right]^{\frac{\mu_{m}}{1-\sigma_{m}}} f_{s}^{\frac{\mu_{s}}{1-\sigma_{s}}}, \\
& P_{2}=\rho\left[\phi_{m} f_{m}+\left(1-f_{m}\right)\right]^{\frac{\mu_{m}}{1-\sigma_{m}}}\left(1-f_{s}\right)^{\frac{\mu_{s}}{1-\sigma_{s}}} .
\end{aligned}
$$

From (31)-(34), we compute the nominal wages of the workers in each region:

$$
\begin{aligned}
\frac{W_{m 1}}{\bar{C}_{0} \sigma_{m}} & =2 \phi_{m} M_{1}\left(\sigma_{s}-\mu_{s}\right)+M_{2}\left\{\sigma_{s}\left[\phi_{m}^{2}+1+\frac{\mu_{m}}{\sigma_{m}}\left(\phi_{m}^{2}-1\right)\right]-\mu_{s}\left(1+\phi_{m}^{2}\right)\right\}, \\
\frac{W_{m 2}}{\bar{C}_{0} \sigma_{m}} & =2 \phi_{m} M_{2}\left(\sigma_{s}-\mu_{s}\right)+M_{1}\left\{\sigma_{s}\left[\phi_{m}^{2}+1+\frac{\mu_{m}}{\sigma_{m}}\left(\phi_{m}^{2}-1\right)\right]-\mu_{s}\left(1+\phi_{m}^{2}\right)\right\}, \\
\frac{W_{s 1}}{\bar{D}_{0} \sigma_{s}} & =S_{2}\left[\sigma_{m}\left(1-\frac{\mu_{s}}{\sigma_{s}}\right)-\mu_{m} \frac{M_{2}-\phi_{m} M_{1}}{\phi_{m} M_{1}+M_{2}}\right], \\
\frac{W_{s 2}}{\bar{D}_{0} \sigma_{s}} & =S_{1}\left[\sigma_{m}\left(1-\frac{\mu_{s}}{\sigma_{s}}\right)-\mu_{m} \frac{M_{1}-\phi_{m} M_{2}}{M_{1}+\phi_{m} M_{2}}\right],
\end{aligned}
$$

where

$$
\begin{aligned}
& \bar{C}_{0}=\frac{\mu_{m} S_{1} S_{2}}{R_{0} \sigma_{m}}, \\
& \bar{D}_{0}=\frac{\mu_{s}\left(M_{1}+\phi_{m} M_{2}\right)\left(\phi_{m} M_{1}+M_{2}\right)}{R_{0} \sigma_{s}},
\end{aligned}
$$

and

$$
\begin{aligned}
R_{0}= & \frac{S_{1} S_{2}}{a \sigma_{m} \sigma_{s}}\left\{\left[\sigma_{m}\left(M_{1}+\phi_{m} M_{2}\right)\left(\sigma_{s}-\mu_{s}\right)-M_{1} \mu_{m} \sigma_{s}\right]\right. \\
& \left.\times\left[\sigma_{m}\left(\phi_{m} M_{1}+M_{2}\right)\left(\sigma_{s}-\mu_{s}\right)-M_{2} \mu_{m} \sigma_{s}\right]-M_{1} M_{2} \mu_{m}^{2} \phi_{m}^{2} \sigma_{s}^{2}\right\} .
\end{aligned}
$$

Dividing the nominal wage in the industrial sector (35) by the regional price level, we obtain the real wages of the industrial workers:

$$
\omega_{m 1}=\frac{2 \phi_{m} f_{m}\left(\sigma_{s}-\mu_{s}\right)+\left(1-f_{m}\right)\left\{\sigma_{s}\left[\phi_{m}^{2}+1+\frac{\mu_{m}}{\sigma_{m}}\left(\phi_{m}^{2}-1\right)\right]-\mu_{s}\left(1+\phi_{m}^{2}\right)\right\}}{R_{m}\left[f_{m}+\left(1-f_{m}\right) \phi_{m}\right]^{\frac{\mu_{m}}{1-\sigma_{m}}} f_{s}^{\frac{\mu_{s}}{1-\sigma_{s}}}}
$$


and

$$
\omega_{m 2}=\frac{2 \phi_{m}\left(1-f_{m}\right)\left(\sigma_{s}-\mu_{s}\right)+f_{m}\left\{\sigma_{s}\left[\phi_{m}^{2}+1+\frac{\mu_{m}}{\sigma_{m}}\left(\phi_{m}^{2}-1\right)\right]-\mu_{s}\left(1+\phi_{m}^{2}\right)\right\}}{R_{m}\left[\phi_{m} f_{m}+\left(1-f_{m}\right)\right]^{\frac{\mu_{m}}{1-\sigma_{m}}}\left(1-f_{s}\right)^{\frac{\mu_{s}}{1-\sigma_{s}}}},
$$

where

$$
\begin{aligned}
R_{m}= & \frac{\rho M}{a \mu_{m} \sigma_{m} \sigma_{s}}\left\{\left\{\sigma_{m}\left[f_{m}+\phi_{m}\left(1-f_{m}\right)\right]\left(\sigma_{s}-\mu_{s}\right)-f_{m} \mu_{m} \sigma_{s}\right\}\right. \\
& \left.\times\left\{\sigma_{m}\left[\phi_{m} f_{m}+\left(1-f_{m}\right)\right]\left(\sigma_{s}-\mu_{s}\right)-\left(1-f_{m}\right) \mu_{m} \sigma_{s}\right\}-f_{m}\left(1-f_{m}\right) \mu_{m}^{2} \phi_{m}^{2} \sigma_{s}^{2}\right\} .
\end{aligned}
$$

With some manipulation, we find that the real wage differential in the industrial sector can be written as:

$$
\omega_{m 1}-\omega_{m 2}=\frac{\mu_{m} K}{\phi_{m}\left[f_{m}^{2}+\left(1-f_{m}\right)^{2}\right] K_{1}+\left(1-f_{m}\right) f_{m} K_{2}} \times\left(\bar{\omega}_{m 1}-\bar{\omega}_{m 2}\right),
$$

where

$$
\begin{aligned}
& K=\frac{\sigma_{m}^{1-\mu_{m}} \sigma_{s}^{1-\mu_{s}}(1-M-S)\left(\sigma_{m}-1\right)^{\mu_{m}}\left(\sigma_{s}-1\right)^{\mu_{s}}}{2 \alpha_{m}^{\frac{\mu_{m}}{\sigma_{m}-1}} \alpha_{s}^{\frac{\mu_{s}}{\sigma_{s}-1}} \beta^{\mu_{m}+\mu_{s}} M^{1-\frac{\mu_{m}}{\sigma_{m}-1}} S^{-\frac{\mu_{s}}{\sigma_{s}-1}}}, \\
& K_{1}=\sigma_{m}\left(\sigma_{s}-\mu_{s}\right)\left[\sigma_{m}\left(\sigma_{s}-\mu_{s}\right)-\sigma_{s} \mu_{m}\right] \\
& K_{2}=\sigma_{m}\left(\sigma_{s}-\mu_{s}\right)\left[\sigma_{m}\left(\sigma_{s}-\mu_{s}\right)\left(1+\phi_{m}^{2}\right)-2 \mu_{m} \sigma_{s}\right]+\mu_{m}^{2} \sigma_{s}^{2}\left(1-\phi_{m}^{2}\right), \\
& \bar{\omega}_{m 1}=\frac{2 \phi_{m} f_{m}\left(\sigma_{s}-\mu_{s}\right)+\left(1-f_{m}\right)\left\{\sigma_{s}\left[\phi_{m}^{2}+1+\frac{\mu_{m}}{\sigma_{m}}\left(\phi_{m}^{2}-1\right)\right]-\mu_{s}\left(\phi_{m}^{2}+1\right)\right\}}{\left[\phi_{m} f_{m}+\left(1-f_{m}\right)\right]^{\frac{\mu_{m}}{1-\sigma_{m}}} f_{s}^{\frac{\mu_{s}}{1-\sigma_{s}}}\left(1-f_{s}\right)^{\frac{\mu_{s}}{1-\sigma_{s}}}}, \\
& \bar{\omega}_{m 2}=\frac{2 \phi_{m}\left(1-f_{m}\right)\left(\sigma_{s}-\mu_{s}\right)+f_{m}\left\{\sigma_{s}\left[\phi_{m}^{2}+1+\frac{\mu_{m}}{\sigma_{m}}\left(\phi_{m}^{2}-1\right)\right]-\mu_{s}\left(\phi_{m}^{2}+1\right)\right\}}{} .
\end{aligned}
$$

Similarly, for the service sector, we obtain:

$$
\omega_{s 1}=\frac{\left[f_{m}+\phi_{m}\left(1-f_{m}\right)\right]\left[\phi_{m} f_{m}+1-f_{m}\right]\left[\sigma_{m}\left(1-\frac{\mu_{s}}{\sigma_{s}}\right)-\mu_{m} \frac{1-f_{m}-\phi_{m} f_{m}}{1-f_{m}+\phi_{m} f_{m}}\right]}{R_{s}\left[f_{m}+\left(1-f_{m}\right) \phi_{m}\right]^{\frac{\mu_{m}}{1-\sigma_{m}}} f_{s}^{1-\frac{\mu_{s}}{\sigma_{s}-1}}}
$$

and

$$
\omega_{s 2}=\frac{\left[f_{m}+\phi_{m}\left(1-f_{m}\right)\right]\left[\phi_{m} f_{m}+1-f_{m}\right]\left[\sigma_{m}\left(1-\frac{\mu_{s}}{\sigma_{s}}\right)-\mu_{m} \frac{f_{m}-\phi_{m}\left(1-f_{m}\right)}{f_{m}+\phi_{m}\left(1-f_{m}\right)}\right]}{R_{s}\left[\phi_{m} f_{m}+\left(1-f_{m}\right)\right]^{\frac{\mu_{m}}{1-\sigma_{m}}}\left(1-f_{s}\right)^{1-\frac{\mu_{s}}{\sigma_{s}-1}}},
$$


where

$$
\begin{aligned}
R_{s}= & \frac{\rho S}{a \sigma_{m} \sigma_{s}}\left\{\left[\sigma_{m}\left[f_{m}+\phi_{m}\left(1-f_{m}\right)\right]\left(\sigma_{s}-\mu_{s}\right)-f_{m} \mu_{m} \sigma_{s}\right]\right. \\
& \left.\times\left[\sigma_{m}\left(\phi_{m} f_{m}+1-f_{m}\right)\left(\sigma_{s}-\mu_{s}\right)-\left(1-f_{m}\right) \mu_{m} \sigma_{s}\right]-f_{m}\left(1-f_{m}\right) \mu_{m}^{2} \phi_{m}^{2} \sigma_{s}^{2}\right\} .
\end{aligned}
$$

Again, after some manipulation, we write the real wage differential in the service sector as:

$$
\omega_{s 1}-\omega_{s 2}=\frac{\mu_{s} K\left\{\phi_{m}\left[f_{m}^{2}+\left(1-f_{m}\right)^{2}\right]+f_{m}\left(1-f_{m}\right)\left(1+\phi_{m}^{2}\right)\right\}}{\phi_{m}\left[f_{m}^{2}+\left(1-f_{m}\right)^{2}\right] K_{1}+\left(1-f_{m}\right) f_{m} K_{2}}\left(\bar{\omega}_{s 1}-\bar{\omega}_{s 2}\right)
$$

where

$$
\begin{aligned}
& \bar{\omega}_{s 1}= \frac{\sigma_{m}\left(1-\frac{\mu_{s}}{\sigma_{s}}\right)-\mu_{m} \frac{1-f_{m}\left(1+\phi_{m}\right)}{1-f_{m}\left(1-\phi_{m}\right)}}{\left[f_{m}+\left(1-f_{m}\right) \phi_{m}\right]^{\frac{\mu_{m}}{1-\sigma_{m}}} f_{s}^{1-\frac{\mu_{s}}{\sigma_{s}-1}}} \\
& \bar{\omega}_{s 2}=\frac{\sigma_{m}\left(1-\frac{\mu_{s}}{\sigma_{s}}\right)-\mu_{m} \frac{f_{m}\left(1+\phi_{m}\right)-\phi_{m}}{f_{m}\left(1-\phi_{m}\right)+\phi_{m}}}{\left[\phi_{m} f_{m}+\left(1-f_{m}\right)\right]^{\frac{\mu_{m}}{1-\sigma_{m}}}\left(1-f_{s}\right)^{1-\frac{\mu_{s}}{\sigma_{s}-1}}} .
\end{aligned}
$$

\section{Long-run equilibrium}

Proof of Lemma 1 Since regions are symmetric, we only study agglomeration in region 1.

When the workers become concentrated in region $1, R_{m}$ converges to:

$$
\lim _{f_{m} \rightarrow 1^{-}} R_{m}=\frac{\rho M \phi_{m}}{a \mu_{m} \sigma_{s}}\left(\sigma_{m} \sigma_{s}-\mu_{s} \sigma_{m}-\mu_{m} \sigma_{s}\right)\left(\sigma_{s}-\mu_{s}\right)>0
$$

Therefore, we have

$$
\lim _{\left(f_{m}, f_{s}\right) \rightarrow\left(1^{-}, 1^{-}\right)} \omega_{m 1}=\frac{2 \phi_{m}\left(\sigma_{s}-\mu_{s}\right)}{\lim _{\left(f_{m}, f_{s}\right) \rightarrow\left(1^{-}, 1^{-}\right)} R_{m}}=\frac{2 a \mu_{m} \sigma_{s}}{\rho M\left(\sigma_{m} \sigma_{s}-\sigma_{m} \mu_{s}-\mu_{m} \sigma_{s}\right)} .
$$

While

$$
\lim _{\left(f_{m}, f_{s}\right) \rightarrow\left(1^{-}, 1^{-}\right)} \omega_{m 2}=\frac{\sigma_{s}\left[\phi_{m}^{2}+1+\frac{\mu_{m}}{\sigma_{m}}\left(\phi_{m}^{2}-1\right)\right]-\mu_{s}\left(1+\phi_{m}^{2}\right)}{\lim _{\left(f_{m}, f_{s}\right) \rightarrow\left(1^{-}, 1^{-}\right)} R_{m} \phi_{m}^{\frac{\mu_{m}}{1-\sigma_{m}}}\left(1-f_{s}\right)^{\frac{\mu_{s}}{1-\sigma_{s}}}} .
$$

The numerator is positive, while the denominator goes to infinity. Thus,

$$
\lim _{\left(f_{m}, f_{s}\right) \rightarrow\left(1^{-}, 1^{-}\right)} \omega_{m 2}=0
$$


We conclude that the industrial workers remain concentrated, as:

$$
\lim _{\left(f_{m}, f_{s}\right) \rightarrow\left(1^{-}, 1^{-}\right)} \omega_{m 1}>\lim _{\left(f_{m}, f_{s}\right) \rightarrow\left(1^{-}, 1^{-}\right)} \omega_{m 2} .
$$

In the service sector, direct substitution of $f_{m}=f_{s}=1$ in (42) leads to:

$$
\lim _{\left(f_{m}, f_{s}\right) \rightarrow\left(1^{-}, 1^{-}\right)} \omega_{s 1}=\frac{\phi_{m}\left[\sigma_{m}\left(1-\frac{\mu_{s}}{\sigma_{s}}\right)+\mu_{m}\right]}{\lim _{\left(f_{m}, f_{s}\right) \rightarrow\left(1^{-}, 1^{-}\right)} R_{s}} .
$$

Substituting $f_{m}=f_{s}=1$ in the expression for $R_{s}$, we obtain the following:

$$
\lim _{\left(f_{m}, f_{s}\right) \rightarrow\left(1^{-}, 1^{-}\right)} R_{s}=\frac{\rho S}{a \sigma_{s}} \phi_{m}\left(\sigma_{m} \sigma_{s}-\sigma_{m} \mu_{s}-\mu_{m} \sigma_{s}\right)\left(\sigma_{s}-\mu_{s}\right)
$$

Hence,

$$
\lim _{\left(f_{m}, f_{s}\right) \rightarrow\left(1^{-}, 1^{-}\right)} \omega_{s 1}=\frac{\sigma_{m}\left(1-\frac{\mu_{s}}{\sigma_{s}}\right)+\mu_{m}}{\frac{\rho S}{a \sigma_{s}}\left(\sigma_{m} \sigma_{s}-\sigma_{m} \mu_{s}-\mu_{m} \sigma_{s}\right)\left(\sigma_{s}-\mu_{s}\right)}>0 .
$$

While

$$
\begin{aligned}
& \lim _{\left(f_{m}, f_{s}\right) \rightarrow\left(1^{-}, 1^{-}\right)} \omega_{s 2}= \frac{\phi_{m}^{\frac{1-\sigma_{m}-\mu_{m}}{1-\sigma_{m}}}\left[\sigma_{m}\left(1-\frac{\mu_{s}}{\sigma_{s}}\right)-\mu_{m}\right]}{\lim _{\left(f_{m}, f_{s}\right) \rightarrow\left(1^{-}, 1^{-}\right)} R_{s}\left(1-f_{s}\right)^{1-\frac{\mu_{s}}{\sigma_{s}-1}}} \\
&= \frac{\phi_{m}^{\frac{\mu_{m}}{\sigma_{m}-1}}\left[\sigma_{m}\left(1-\frac{\mu_{s}}{\sigma_{s}}\right)-\mu_{m}\right]}{\frac{\rho S}{a \sigma_{s}}\left(\sigma_{m} \sigma_{s}-\sigma_{m} \mu_{s}-\mu_{m} \sigma_{s}\right)\left(\sigma_{s}-\mu_{s}\right)} \\
& \lim _{\left(f_{m}, f_{s}\right) \rightarrow\left(1^{-}, 1^{-}\right)}\left(1-f_{s}\right)^{\frac{\sigma_{s}-1-\mu_{s}}{1-\sigma_{s}}} .
\end{aligned}
$$

The real wage of the service workers in the empty region tends to zero if $\sigma_{s}<1+\mu_{s}$ and to plus infinity if $\sigma_{s}>1+\mu_{s}$. Notice also that with $\sigma_{s}=1+\mu_{s}$, we have $\omega_{s 1}>\omega_{s 2}$ (in the limit).

We conclude that agglomeration of both sectors in a single region is an equilibrium if and only if $\mu_{s} \geq \sigma_{s}-1$.

Proof of Lemma 2 From Eq. (42), in region 1, the real wage in the service sector, $w_{s}$, is proportional to $f_{s}^{\frac{\mu_{s}}{\sigma_{s}-1}-1}$. When $\mu_{s}<\sigma_{s}-1$, it is decreasing with $f_{s}$, tending to $+\infty$ as $f_{s}$ decreases to 0 .

By symmetry, in region 2, the real wage in the service sector, $w_{s 2}$, is increasing with $f_{s}$ (decreasing with $\left.1-f_{s}\right)$, tending to $+\infty$ as $f_{s}$ increases to $1\left(1-f_{s}\right.$ decreases to 0 ).

Therefore, an increase in $f_{s}$ decreases the difference between $w_{s 1}$ and $w_{s 2}$. As the share of services increases from 0 to $1, w_{s 1}-w_{s 2}$ decreases from $+\infty$ to $-\infty$. 
Proof of Lemma 3 Since regions are symmetric, we only study the case in which all the industrial activity is concentrated in region 1 .

When $f_{m}=1$, the difference between the real wages of the service sector workers is:

$$
\omega_{s 1}-\omega_{s 2}=\frac{\mu_{s} K}{K_{1}}\left[\frac{\sigma_{m}\left(1-\frac{\mu_{s}}{\sigma_{s}}\right)+\mu_{m}}{f_{s}^{1-\frac{\mu_{s}}{\sigma_{s}-1}}}-\frac{\sigma_{m}\left(1-\frac{\mu_{s}}{\sigma_{s}}\right)-\mu_{m}}{\phi_{m}^{\frac{\mu_{m}}{1-\sigma_{m}}}\left(1-f_{s}\right)^{1-\frac{\mu_{s}}{\sigma_{s}-1}}}\right] .
$$

We begin our proof by calculating the values of $f_{s} \in(0,1)$ for which $\omega_{s 1}-\omega_{s 2}=0$. Since $K$ and $K_{1}$ are strictly positive and finite:

$$
\begin{aligned}
& 0=\frac{\sigma_{m}\left(1-\frac{\mu_{s}}{\sigma_{s}}\right)+\mu_{m}}{f_{s}^{1-\frac{\mu_{s}}{\sigma_{s}-1}}}-\frac{\sigma_{m}\left(1-\frac{\mu_{s}}{\sigma_{s}}\right)-\mu_{m}}{\phi_{m}^{\frac{\mu_{m}}{1-\sigma_{m}}}\left(1-f_{s}\right)^{1-\frac{\mu_{s}}{\sigma_{s}-1}}} \\
& \Leftrightarrow \frac{1-f_{s}}{f_{s}}=\left\{\frac{\sigma_{m}\left(1-\frac{\mu_{s}}{\sigma_{s}}\right)-\mu_{m}}{\phi_{m}^{\frac{\mu_{m}}{1-\sigma_{m}}}\left[\sigma_{m}\left(1-\frac{\mu_{s}}{\sigma_{s}}\right)+\mu_{m}\right]}\right\}^{\frac{\sigma_{s}-1}{\sigma_{s}-1-\mu_{s}}} .
\end{aligned}
$$

Simplifying:

$$
f_{S}=\frac{1}{\left\{\frac{\sigma_{m}\left(1-\frac{\mu_{s}}{\sigma_{s}}\right)-\mu_{m}}{\phi_{m}^{\frac{\mu_{m}}{1-\sigma_{m}}}\left[\sigma_{m}\left(1-\frac{\mu_{s}}{\sigma_{s}}\right)+\mu_{m}\right]}\right\}^{\frac{\sigma_{s}-1}{\sigma_{s}-1-\mu_{s}}}+1} .
$$

Notice that since $\phi_{m}^{\frac{\mu_{m}}{1-\sigma_{m}}}>1$, we have

$$
0<\frac{\sigma_{m}\left(1-\frac{\mu_{s}}{\sigma_{s}}\right)-\mu_{m}}{\phi_{m}^{\frac{\mu_{m}}{1-\sigma_{m}}}\left[\sigma_{m}\left(1-\frac{\mu_{s}}{\sigma_{s}}\right)+\mu_{m}\right]}<1
$$

Therefore, since $\sigma_{s}>\mu_{s}+1$, we have

$$
0<\left\{\frac{\sigma_{m}\left(1-\frac{\mu_{s}}{\sigma_{s}}\right)-\mu_{m}}{\phi_{m}^{\frac{\mu_{m}}{1-\sigma_{m}}}\left[\sigma_{m}\left(1-\frac{\mu_{s}}{\sigma_{s}}\right)+\mu_{m}\right]}\right\}^{\frac{\sigma_{s}-1}{\sigma_{s}-1-\mu_{s}}}<1
$$

and

$$
\frac{1}{2}<f_{s}<1
$$

It remains to verify the equilibrium condition for the industrial sector. 
When the industrial workers are concentrated in region 1 , the difference between the real wages in the two regions is:

$$
\omega_{m 1}-\omega_{m 2}=\frac{\mu_{m} K}{\phi_{m} K_{1}}\left\{\frac{2 \phi_{m}\left(\sigma_{s}-\mu_{s}\right)}{f_{s}^{\frac{\mu_{s}}{1-\sigma_{s}}}}-\frac{\sigma_{s}\left[\phi_{m}^{2}+1+\frac{\mu_{m}}{\sigma_{m}}\left(\phi_{m}^{2}-1\right)\right]-\mu_{s}\left(\phi_{m}^{2}+1\right)}{\phi_{m}^{\frac{\mu_{m}}{1-\sigma_{m}}}\left(1-f_{s}\right)^{\frac{\mu_{s}}{1-\sigma_{s}}}}\right\} .
$$

Then, $\omega_{m 1}-\omega_{m 2}>0$ if and only if:

$$
\begin{aligned}
\frac{2 \phi_{m}\left(\sigma_{s}-\mu_{s}\right)}{f_{s}^{\frac{\mu_{s}}{1-\sigma_{s}}}}>\frac{\sigma_{s}\left[\phi_{m}^{2}+1+\frac{\mu_{m}}{\sigma_{m}}\left(\phi_{m}^{2}-1\right)\right]-\mu_{s}\left(\phi_{m}^{2}+1\right)}{\phi_{m}^{\frac{\mu_{m}}{1-\sigma_{m}}}\left(1-f_{s}\right)^{\frac{\mu_{s}}{1-\sigma_{s}}}} \\
\Leftrightarrow\left(\frac{1-f_{s}}{f_{s}}\right)^{\frac{\mu_{s}}{1-\sigma_{s}}}>\frac{\sigma_{s}\left[\phi_{m}^{2}+1+\frac{\mu_{m}}{\sigma_{m}}\left(\phi_{m}^{2}-1\right)\right]-\mu_{s}\left(\phi_{m}^{2}+1\right)}{2 \phi_{m}\left(\sigma_{s}-\mu_{s}\right) \phi_{m}^{\frac{\mu_{m}}{1-\sigma_{m}}}}
\end{aligned}
$$

Replacing Eq. (44), we obtain the following:

$$
\left\{\frac{\sigma_{m}\left(1-\frac{\mu_{s}}{\sigma_{s}}\right)-\mu_{m}}{\phi_{m}^{\frac{\mu_{m}}{1-\sigma_{m}}}\left[\sigma_{m}\left(1-\frac{\mu_{s}}{\sigma_{s}}\right)+\mu_{m}\right]}\right\}^{\frac{-\mu_{s}}{\sigma_{s}-1-\mu_{s}}}>\frac{\sigma_{s}\left[\phi_{m}^{2}+1+\frac{\mu_{m}}{\sigma_{m}}\left(\phi_{m}^{2}-1\right)\right]-\mu_{s}\left(\phi_{m}^{2}+1\right)}{2\left(\sigma_{s}-\mu_{s}\right) \phi_{m}^{\frac{\mu_{m}}{1-\sigma_{m}}+1}} .
$$

Rearranging:

$$
\begin{aligned}
& {\left[\frac{\sigma_{m}\left(1-\frac{\mu_{s}}{\sigma_{s}}\right)-\mu_{m}}{\sigma_{m}\left(1-\frac{\mu_{s}}{\sigma_{s}}\right)+\mu_{m}}\right]^{\frac{-\mu_{s}}{\sigma_{s}-1-\mu_{s}}} \phi_{m}^{1-\frac{\mu_{m}\left(\sigma_{s}-1\right)}{\left(\sigma_{m}-1\right)\left(\sigma_{s}-1-\mu_{s}\right)}}} \\
& -\frac{\phi_{m}^{2}\left[\sigma_{s}\left(1+\frac{\mu_{m}}{\sigma_{m}}\right)-\mu_{s}\right]+\sigma_{s}\left(1-\frac{\mu_{m}}{\sigma_{m}}\right)-\mu_{s}}{2\left(\sigma_{s}-\mu_{s}\right)}>0 .
\end{aligned}
$$

Agglomeration of all the industrial activity in a region and partial agglomeration dispersion of the service activity are a steady state when the above condition is satisfied. Lemma 2 provides the stability condition, guaranteeing that it is an equilibrium.

Proof of Lemma 4 (i) Since regions are symmetric, we only need to study the case in which industry is concentrated in region 1 and services are concentrated in region 2 . We look at points near $\left(f_{m}, f_{s}\right)=(1,0)$ and at what happens when first $f_{m} \rightarrow 1$ and then $f_{s} \rightarrow 0$.

The difference between the real wages in the industrial sector when all the industry is located in region 1 and all the services are located in region 2 is, using (41):

$$
\omega_{m 1}-\omega_{m 2}=\frac{\mu_{m} K}{\phi_{m} K_{1}}\left(\bar{\omega}_{m 1}-\bar{\omega}_{m 2}\right)
$$


Notice that the constants $K$ and $K_{1}$ are strictly positive and finite.

Observe also that when $\left(f_{m}, f_{s}\right)=(1,0)$, we have $\bar{\omega}_{m 1}=0$ and $\bar{\omega}_{m 2}>0$. Therefore, $\omega_{m 1}<\omega_{m 2}$.

Agglomeration of each sector in a different region is never an equilibrium.

(ii) Since regions are symmetric, it is enough to study the case in which services are symmetrically dispersed while the industry is concentrated in region 1 .

The difference between the real wages in the service sector when $f_{s}=0.5$ and $f_{m}=1$ is:

$$
\omega_{s 1}-\omega_{s 2}=\frac{\mu_{s} K}{K_{1}}\left(\bar{\omega}_{s 1}-\bar{\omega}_{s 2}\right)
$$

The constants $K$ and $K_{1}$ are strictly positive and finite.

With $\left(f_{s}, f_{m}\right)=\left(\frac{1}{2}, 1\right)$, we have:

$$
\bar{\omega}_{s 2}=\frac{\sigma_{m}\left(1-\frac{\mu_{s}}{\sigma_{s}}\right)-\mu_{m}}{\phi_{m}^{\frac{\mu_{m}}{1-\sigma_{m}}} \frac{1}{2}^{\frac{\sigma_{s}-1-\mu_{s}}{\sigma_{s}-1}}} \text { and } \bar{\omega}_{s 1}=\frac{\sigma_{s}\left(1-\frac{\mu_{s}}{\sigma_{s}}\right)+\mu_{m}}{\left(\frac{1}{2}\right)^{\frac{\sigma_{s}-1-\mu_{s}}{\sigma_{s}-1}}} .
$$

Therefore, $\bar{\omega}_{s 2}<\bar{\omega}_{s 1}$ is equivalent to:

$$
\left(1-\phi_{m}^{\frac{\mu_{m}}{1-\sigma_{m}}}\right) \sigma_{m}\left(1-\frac{\mu_{s}}{\sigma_{s}}\right)<\mu_{m}\left(\phi_{m}^{\frac{\mu_{m}}{1-\sigma_{m}}}+1\right)
$$

which is true because the right-hand side of this inequality is positive, whereas the left-hand side is negative. Therefore, $\omega_{s 2}<\omega_{s 1}$.

Symmetric dispersion of services with agglomeration of industry cannot be an equilibrium.

(iii) Since regions are symmetric, it is enough to study the case in which industry is dispersed while services are concentrated in region $2\left(f_{s}=0\right)$.

From expression (41), the difference between the real wages in the industrial sector is:

$$
\omega_{m 1}-\omega_{m 2}=\frac{\mu_{m} K}{\phi_{m}\left[f_{m}^{2}+\left(1-f_{m}\right)^{2}\right] K_{1}+\left(1-f_{m}\right) f_{m} K_{2}}\left(\bar{\omega}_{m 1}-\bar{\omega}_{m 2}\right) .
$$

With $f_{s}=0$, we have $\bar{\omega}_{m 1}=0$ and $\bar{\omega}_{m 2}>0$.

This implies that $\omega_{m 1}<\omega_{m 2}$, because $K, K_{1}$ and $K_{2}$ are strictly positive and finite.

Dispersion of industry with agglomeration of services cannot be an equilibrium.

Proof of Lemma 5 We want to prove that $\frac{\partial\left(\omega_{m 1}-\omega_{m 2}\right)}{\partial f_{s}}>0$.

From (41), we know that the sign of $\frac{\partial\left(\bar{\omega}_{m 1}-\bar{\omega}_{m 2}\right)}{\partial f_{s}}$ is the same. 
Calculating the partial derivatives:

$$
\begin{aligned}
\frac{\partial \bar{\omega}_{m 1}}{\partial f_{s}} & =\frac{2 \phi_{m} f_{m}\left(\sigma_{s}-\mu_{s}\right)+\left(1-f_{m}\right)\left\{\sigma_{s}\left[\phi_{m}^{2}+1+\frac{\mu_{m}}{\sigma_{m}}\left(\phi_{m}^{2}-1\right)\right]-\mu_{s}\left(\phi_{m}^{2}+1\right)\right\}}{\frac{\sigma_{s}-1}{\mu_{s}}\left[f_{m}+\left(1-f_{m}\right) \phi_{m}\right]^{\frac{\mu_{m}}{1-\sigma_{m}}} f_{s}^{1-\frac{\mu_{s}}{\sigma_{s}-1}}}, \\
\frac{\partial \bar{\omega}_{m 2}}{\partial f_{s}} & =-\frac{2 \phi_{m}\left(1-f_{m}\right)\left(\sigma_{s}-\mu_{s}\right)+f_{m}\left\{\sigma_{s}\left[\phi_{m}^{2}+1+\frac{\mu_{m}}{\sigma_{m}}\left(\phi_{m}^{2}-1\right)\right]-\mu_{s}\left(\phi_{m}^{2}+1\right)\right\}}{\frac{\sigma_{s}-1}{\mu_{s}}\left[\phi_{m} f_{m}+\left(1-f_{m}\right)\right]^{\frac{\mu_{m}}{1-\sigma_{m}}}\left(1-f_{s}\right)^{1-\frac{\mu_{s}}{\sigma_{s}-1}}} .
\end{aligned}
$$

Substituting $\left(f_{s}, f_{m}\right)=\left(\frac{1}{2}, \frac{1}{2}\right)$, we find that:

$$
\frac{\partial\left(\bar{\omega}_{m 1}-\bar{\omega}_{m 2}\right)}{\partial f_{s}}=\frac{2 \phi_{m}\left(\sigma_{s}-\mu_{s}\right)+\left\{\sigma_{s}\left[\phi_{m}^{2}+1+\frac{\mu_{m}}{\sigma_{m}}\left(\phi_{m}^{2}-1\right)\right]-\mu_{s}\left(\phi_{m}^{2}+1\right)\right\}}{\frac{\sigma_{s}-1}{\mu_{s}}\left[\frac{1}{2}\left(1+\phi_{m}\right)\right]^{\frac{\mu_{m}}{1-\sigma_{m}}}\left(\frac{1}{2}\right)^{1-\frac{\mu_{s}}{\sigma_{s}-1}}}>0 .
$$

Proof of Lemma 6 We want to prove that $\frac{\partial\left(\omega_{s 1}-\omega_{s 2}\right)}{\partial f_{m}}>0$. Using Eq. (43), we determine the partial derivative:

$$
\begin{aligned}
\frac{\partial\left(\omega_{s 1}-\omega_{s 2}\right)}{\partial f_{m}}= & \frac{\partial}{\partial f_{m}}\left[\frac{\mu_{s} K\left\{\phi_{m}\left[f_{m}^{2}+\left(1-f_{m}\right)^{2}\right]+f_{m}\left(1-f_{m}\right)\left(1+\phi_{m}^{2}\right)\right\}}{\phi_{m}\left[f_{m}^{2}+\left(1-f_{m}\right)^{2}\right] K_{1}+\left(1-f_{m}\right) f_{m} K_{2}}\right]\left(\bar{\omega}_{s 1}-\bar{\omega}_{s 2}\right) \\
& +\frac{\partial\left(\bar{\omega}_{s 1}-\bar{\omega}_{s 2}\right)}{\partial f_{m}}\left[\frac{\mu_{s} K\left\{\phi_{m}\left[f_{m}^{2}+\left(1-f_{m}\right)^{2}\right]+f_{m}\left(1-f_{m}\right)\left(1+\phi_{m}^{2}\right)\right\}}{\phi_{m}\left[f_{m}^{2}+\left(1-f_{m}\right)^{2}\right] K_{1}+\left(1-f_{m}\right) f_{m} K_{2}}\right] .
\end{aligned}
$$

Since we are evaluating the derivative at $\left(f_{s}, f_{m}\right)=\left(\frac{1}{2}, \frac{1}{2}\right)$, the first term disappears:

$$
\frac{\partial\left(\omega_{s 1}-\omega_{s 2}\right)}{\partial f_{m}}=\frac{\partial\left(\bar{\omega}_{s 1}-\bar{\omega}_{s 2}\right)}{\partial f_{m}}\left[\frac{\mu_{s} K\left(2 \phi_{m}+1+\phi_{m}^{2}\right)}{2 \phi_{m} K_{1}+K_{2}}\right] .
$$

The partial derivative of $\bar{\omega}_{s}$ with respect to $f_{m}$ is:

$$
\begin{aligned}
\frac{\partial \bar{\omega}_{s 1}}{\partial f_{m}}= & \frac{1}{\left[f_{m}+\left(1-f_{m}\right) \phi_{m}\right]^{\frac{\mu_{m}}{1-\sigma_{m}}} f_{s}^{1-\frac{\mu_{s}}{\sigma_{s}-1}}} \\
& \times \mu_{m} \frac{\left(1+\phi_{m}\right)\left[1-f_{m}\left(1-\phi_{m}\right)\right]+\left(\phi_{m}-1\right)\left[1-f_{m}\left(1+\phi_{m}\right)\right]}{\left[1-f_{m}\left(1-\phi_{m}\right)\right]^{2}} \\
& +\frac{1}{\left\{\left[f_{m}+\left(1-f_{m}\right) \phi_{m}\right]^{\frac{\mu_{m}}{1-\sigma_{m}}} f_{s}^{1-\frac{\mu_{s}}{\sigma_{s}-1}}\right\}^{2}} \\
& \times \frac{\mu_{m}}{\sigma_{m}-1}\left[f_{m}+\left(1-f_{m}\right) \phi_{m}\right]^{\frac{\mu_{m}}{1-\sigma_{m}}-1} f_{s}^{1-\frac{\mu_{s}}{\sigma_{s}-1}}\left(1-\phi_{m}\right) \\
& \times\left[\sigma_{m}\left(1-\frac{\mu_{s}}{\sigma_{s}}\right)-\mu_{m} \frac{1-f_{m}\left(1+\phi_{m}\right)}{1-f_{m}\left(1-\phi_{m}\right)}\right] .
\end{aligned}
$$


Substituting $\left(f_{s}, f_{m}\right)=\left(\frac{1}{2}, \frac{1}{2}\right)$ :

$$
\begin{gathered}
\left.\frac{\partial \bar{\omega}_{s 1}}{\partial f_{m}}\right|_{\left(f_{s}, f_{m}\right)=\left(\frac{1}{2}, \frac{1}{2}\right)}=\frac{\mu_{m}\left[\left(1+\phi_{m}\right)\left(\frac{1}{2}+\frac{1}{2} \phi_{m}\right)+\left(\phi_{m}-1\right)\left(\frac{1}{2}-\frac{1}{2} \phi_{m}\right)\right]}{\left(\frac{1}{2}+\frac{1}{2} \phi_{m}\right)^{\frac{\mu_{m}}{1-\sigma_{m}}} 2^{-1+\frac{\mu_{s}}{\sigma_{s}-1}}\left(\frac{1}{2}+\frac{1}{2} \phi_{m}\right)^{2}} \\
+\frac{\frac{\mu_{m}}{\sigma_{m}-1}\left(\frac{1}{2}+\frac{1}{2} \phi_{m}\right)^{\frac{\mu_{m}}{1-\sigma_{m}}-1} 2^{-1+\frac{\mu_{s}}{\sigma_{s}-1}}\left(1-\phi_{m}\right)}{\left[\left(\frac{1}{2}+\frac{1}{2} \phi_{m}\right)^{\frac{\mu_{m}}{1-\sigma_{m}}} 2^{-1+\frac{\mu_{s}}{\sigma_{s}-1}}\right]^{2}}\left[\sigma_{m}\left(1-\frac{\mu_{s}}{\sigma_{s}}\right)-\mu_{m} \frac{\frac{1}{2}-\frac{1}{2} \phi_{m}}{\frac{1}{2}+\frac{1}{2} \phi_{m}}\right] .
\end{gathered}
$$

Both terms are positive; therefore, $\frac{\partial \omega_{s 1}}{\partial f_{m}}>0$.

positive.

By symmetry, $\frac{\partial \omega_{s 2}}{\partial f_{m}}=-\frac{\partial \omega_{s 1}}{\partial f_{m}}$. Hence, we conclude that $\left.\frac{\partial\left(\omega_{s 1}-\omega_{s 2}\right)}{\partial f_{m}}\right|_{f_{m}=f_{s}=\frac{1}{2}}$ is

\section{References}

Baldwin R, Martin P, Ottaviano G (2001) Income divergence, trade, and industrialization: the geography of growth take-offs. J Econ Growth 6:5-37

Baldwin R, Forslid R, Martin P, Ottaviano G, Robert-Nicoud F (2003) Economic geography and public policy. Princeton University Press, Princeton

Behrens K (2004) Agglomeration without trade: how non-traded goods shape the space-economy. J Urban Econ 55:68-92

Cerina F, Mureddu F (2009) Is agglomeration really good for growth? Global efficiency and interregional equity. Working Paper CRENoS 2009/13

Davis DR (1998) The home market, trade, and industrial structure. Am Econ Rev 88:1264-1276

Davis DR, Weinstein DE (2003) Market access, economic geography and comparative advantage: an empirical test. J Int Econ 59:1-23

Forslid R, Ottaviano GIP (2003) An analytically solvable core-periphery model. J Econ Geogr 3:229-240 Fujita M, Krugman P, Venables AJ (2001) The spatial economy. MIT press, London

Helpman E (1998) The size of regions. Working Paper 14-95, The Foerder Institute for Economic Research Krugman P (1991) Increasing returns and economic geography. J Polit Econ 99:483-499

Pflüger M, Südekum J (2008) Integration, agglomeration and welfare. J Urban Econ 63:544-566

Puga D (1999) The rise and fall of regional inequalities. Eur Econ Rev 43:303-334

Südekum J (2006) Agglomeration and regional costs of living. J Reg Sci 46:529-543

Tabuchi T, Thisse J-F (2006) Regional specialization, urban hierarchy, and commuting costs. Int Econ Rev 47:1295-1317

Takayama T, Judge GG (1971) Spatial and temporal price and allocation models. North Holland, Amsterdam

Von Thünen JH (1826) Der isolierte staat. Partial english translation (1966) Von Thünen's Isolated State. Pergamon Press, Oxford 